\title{
O ciclo de alta nos preços das commodities e a economia brasileira: uma análise dos mecanismos externos de transmissão entre 2002 e 2014 *
}

\author{
Sabrina Monique Schenato Bredow ** \\ Marcos Tadeu Caputi Lélis *** \\ André Moreira Cunha
}

\section{Resumo}

Este trabalho analisa a influência do recente ciclo de alta dos preços das commodities sobre a entrada de capital externo no Brasil (exportações, investimentos em carteira e IED). Para o alcance desse objetivo, foram utilizadas duas metodologias econométricas diferentes: Modelos de Mudanças de Regimes Markovianos e Modelo Vetorial de Correção de Erros (VAR/VEC). Nossos resultados sugerem que: (i) o recente período de alta dos preços das commodities ocorreu entre 2002 e 2014; (ii) os regimes de alta estimados para as exportações, IED e Investimento Estrangeiro em Carteira (IEC) ocorreram em períodos similares ao observado para a série dos preços das commodities; e (iii) os modelos VAR/VEC indicam a alta dos preços das commodities influenciou significativamente a entrada de capital externo no Brasil, particularmente nas vendas externas de mercadorias e nos fluxos financeiros de curto prazo.

Palavras-chave: Preços das commodities; Exportações; Fluxos de capitais; Brasil; Modelos de mudança de regime Markoviano e VAR/VEC.

\begin{abstract}
Super cycle of commodity prices and the Brazilian economy: an analysis of the external transmission mechanisms between 2002 and 2014

This study analyzes the influence of the recent cycle of high commodity prices on foreign capital inflows into Brazil (exports, portfolio flows and FDI). To achieve this goal, two different econometric methodologies were used: The Markov-Switching Model and The Vector Error Correction Model (VAR/VEC). Our main results are: (i) the price cycle occurred between 2002 and 2014; (ii) Markovian regimes for exports, portfolio flows and FDI converge to the commodity prices' regime; and (iii) VAR/VEC models show that the cycle of high commodity prices significantly influenced the foreign capital inflows into Brazil, with the most significant effects occurring through trade and short-term capital inflows.
\end{abstract}

Keywords: Commodity prices; Exports; Capital flows; Brazil; Markov-Switching and VAR/VEC. JEL F43, F14, O11.

\footnotetext{
* Artigo recebido em 9 de maio de 2016 e aprovado em 9 de outubro de 2016.

** Mestre em Economia pela Universidade do Vale do Rio dos Sinos (Unisinos) / Doutoranda em Economia do Programa de Pós-Graduação em Economia da Universidade Federal do Rio Grande do Sul (PPGE/UFRGS), Porto Alegre, RS, Brasil. E-mail: sabrinabredow@gmail.com.

${ }^{* * *}$ Professor do Programa de Pós-Graduação em Economia da Unisinos, São Leopoldo, RS, Brasil. E-mail: mcaputi@uol.com.br.

${ }^{* * * *}$ Professor Associado do Departamento de Economia e Relações Internacionais (DERI/UFRGS) e Pesquisador do Conselho Nacional de Desenvolvimento Científico e Tecnológico (CNPq), Porto Alegre, RS, Brasil. E-mail: andre.cunha@ufrgs.br.
} 


\section{Introdução}

A partir de 2002 e até recentemente, observou-se a emergência de um longo ciclo de alta nos preços internacionais das commodities $^{l}$, que coincidiu com um processo generalizado de melhoria no desempenho econômico das economias especializadas na produção e exportação de recursos naturais (World Bank, 2008; Sinnot; Nash; De la Torre, 2010; IMF, 2015). Da mesma forma, a reversão de tal boom ou "superciclo" esteve associado à perda de dinamismo daquelas economias. Tais movimentos reacenderam o debate em torno da relação entre desenvolvimento e recursos naturais, de um modo geral, e das vantagens e desvantagens da especialização produtiva e comercial externa com esse tipo de viés. A literatura especializada no tema, extensa e controversa, propõe teses distintas sobre as repercussões potenciais desse padrão de especialização: por um lado, argumentos derivados dos modelos clássico e neoclássico de comércio internacional postulam que o crescimento econômico e o bem-estar dos consumidores são potencializados pela especialização e que esta deriva da exploração das distintas dotações de fatores de produção; por outro lado, críticos a tais modelos sugerem que características intrínsecas dos mercados de commodities, no que se refere, principalmente, às dinâmicas de preços, introduz maior volatilidade e menor potencial de crescimento de longo prazo para a renda (Prates, 2007; Sinnot; Nash; De la Torre, 2010; Black, 2015).

É neste contexto que o presente trabalho tem por objetivo central avaliar a influência da evolução nos preços das commodities sobre a entrada de divisas no Brasil. É por meio do comércio internacional e dos movimentos de capitais que se explicitam alguns dos canais de transmissão ${ }^{2}$ dos movimentos daqueles preços sobre as economias que produzem e negociam recursos naturais e/ou produtos processados a partir daqueles. Para tanto, foi testada a influência deste ciclo sobre os três grandes

(1) Assume-se aqui que commodities são bens diretamente originados na natureza, como minérios, petróleo, produtos agropecuários, florestais, e seus derivados a partir de algum grau de processamento industrial. Os produtos negociados em bolsa de valores, como a bolsa de Chicago, fazem parte deste grupo. Porém, ter sua negociação padronizada em mercados organizados não é a característica exclusiva para que um bem seja considerado commodity neste trabalho. Assim, por exemplo, o CRB - Commodity Research Bureau (http://www.crbtrader.com/) - considera mais de vinte produtos negociados em bolsa para compor seu índice, incluindo metais, óleo, produtos agrícolas, têxteis e fibras. No caso do FMI, são mais de cinquenta produtos, ver: (http://www.imf.org/external/np/res/commod/index.asp). A Unctad considera commodities os seguintes grupos de produtos (SITC): $0+1+2+3+4+667+68+971$ "Commodities at a glance, March, 2011, http://www.unctad.org/en/docs/suc20112_en.pdf). O Banco Mundial coleta dados de commodities desde 1960 com um amplo conjunto de bens, com quase 200 séries temporais (http://data.worldbank.org/data-catalog/commodityprice-data).

(2) Black (2013) sugere que há pelo menos cinco canais de transmissão, a saber: (i) efeito-preço nas exportações de commodities; (ii) efeito-quantum nas exportações de manufaturados para outros países exportadores de commodities; (iii) resultados no emprego; (iv) a possibilidade de se elevarem as importações e, portanto, atenderse à demanda doméstica; e (v) a elevação das receitas fiscais. World Bank (2008), Sinnot, Nash e De La Torre (2010), Ledernan e Maloney (2010); IMF (2015), dentre outros, apontam para a mesma direção e enfatizam outros efeitos, como na formação bruta de capital, nos fluxos de capitais, etc. 
agregados do Balanço de Pagamentos (BP) brasileiro, que representam as formas de ingresso de capital externo no país, que são as exportações de mercadorias, o investimento em carteira (IEC) e o investimento estrangeiro direto (IED). Para verificar aqueles canais de transmissão, foram utilizadas duas estratégias empíricas distintas: (i) inicialmente, com as mudanças de regime de Markov, foi possível identificar a dinâmica cíclica dos preços das commodities e das variáveis representativas das distintas formas de entrada de divisas no país e, com isso, podese estabelecer a periodização de referência para análise dos dados; (ii) na sequência, o emprego da metodologia de vetores autorregressivos (VAR/VEC) permitiu a estimação de modelos comportamentais para cada agregado selecionado do BP. Os resultados encontrados permitem sugerir que o recente período de alta daqueles preços incrementou a entrada de divisas no Brasil, sendo que os efeitos diretos mais fortes foram observados por meio das exportações e do IEC. Com isso, espera-se ter contribuído para o avanço da compreensão sobre os impactos do ciclo de alta de preços das commodities na economia brasileira.

Além desta breve Introdução, o trabalho está organizado da seguinte forma: a seção 1 revisa a literatura teórica e empírica; a seção 2 traz as evidências para o caso do Brasil; a seção 3 sintetiza os resultados e apresenta as conclusões principais.

\section{Canais de transmissão das variações nos preços das commodities: breve revisão da literatura}

A possibilidade de a especialização na produção e exportação de recursos naturais sustentar o crescimento de longo prazo das economias é um tema amplo e controverso. $\mathrm{Na}$ origem da economia política clássica - particularmente nos trabalhos dos seus pais-fundadores, Adam Smith e David Ricardo, havia uma conexão virtuosa entre expansão dos mercados, transformações produtivas internas às empresas - como no exemplo da fábrica de alfinetes smithiana - e especialização produtiva e comercial externa (Reinert, 2005; Unido, 2013; Black, 2015). Derivavase disso a defesa do livre comércio e a crítica às políticas mercantilistas. Por outro lado, perspectivas críticas a tal padrão de especialização passaram a ganhar força desde Alexander Hamilton, no alvorecer da formação do Estado Nacional estadunidense, passando por Friedrich List e sua preocupação com o atraso relativo da Alemanha frente à Inglaterra, e chegando às teorias do desenvolvimento do póssegunda guerra mundial, que enfatizaram a indústria de transformação enquanto o "motor do crescimento" (Kaldor, 1967; Bielschowsky, 2000; Szirmai, 2005, Reinert, 2005).

Mais recentemente, Sachs e Warner $(1995,1997)$ sugeriram haver uma "maldição dos recursos naturais", expressa na relação negativa entre o crescimento no longo prazo e a participação das exportações intensivas em recursos naturais como proporção da renda (ou das exportações totais). Da mesma forma, estudos 
baseados na economia da complexidade (IMF, 2015) indicam que, controlados para outros determinantes do crescimento de longo prazo, a diversificação comercial que é um reflexo da produtiva - e a maior sofisticação tecnológica geram maior dinamismo nas economias. Pesquisas sobre os ciclos de negócios nas economias avançadas e emergentes constatam que o segundo grupo apresenta maior volatilidade macroeconômica e vulnerabilidade à eclosão de crises. Tal padrão adviria da forma como se propagam os choques nos termos de intercâmbio e das paradas súbitas de capital. A especialização na produção e exportação em recursos naturais afetaria negativamente tanto a dinâmica de curto e médio prazo, capturada nos ciclos, quanto a tendência de expansão no longo prazo, por comprometer a formação bruta de capital (Calderón; Fuentes, 2010; Caldentey; Titelman; Carvallo, 2013; IMF, 2015).

Por que há, em parte da literatura, restrições em torno da especialização em recursos naturais? "Pessimistas" sugerem que os setores econômicos especializados na produção e, em geral, exportação de recursos naturais, especialmente minérios e petróleo, produzem rendas elevadas capazes de gerar taxas de lucratividade muito superiores às do conjunto da economia. Por sua vez, tais rendas, quando provenientes de fora do país, levam a processos de forte apreciação da moeda nacional frente às divisas internacionais de referência. Neste contexto, a alteração de preços relativos entre bens comercializáveis e não comercializáveis tende a desestimular a diversificação da estrutura produtiva e de comércio exterior. A assim chamada "doença holandesa" seria a manifestação deste efeito perverso da valorização da moeda nacional diante do boom de influxo de divisas originado na exportação de commodities. Ademais, a velha literatura desenvolvimentista e seus herdeiros contemporâneos apontam para os limites dos setores intensivos em recursos naturais em multiplicar renda, emprego e impostos por meio do nucleamento de cadeias produtivas mais complexas e intensivas em tecnologia (Prebisch, 1984; Krugman, 1993; Bielschowsky, 2000; Unido, 2013, 2016).

Assumindo-se válida a hipótese Prebisch-Singer ${ }^{3}$ de tendência secular à queda nos termos de intercâmbio, os países exportadores de recursos naturais se defrontariam, recorrentemente, com choques negativos nos termos de intercâmbio (a relação entre preços das exportações e das importações) e, com isso, dificuldades estruturais no BP. Ademais, a menor elasticidade-renda dos produtos primários vis$\grave{a}$-vis as manufaturas limitaria a expansão relativa dos mercados de commodities. A

(3) A hipótese desenvolvida por Prebisch e Singer, de forma independente, indica que, no longo prazo, existe uma tendência de que os preços das commodities influenciem negativamente as receitas com exportações dos países; sendo esta influência tão maior quanto mais concentrada for a pauta exportadora dos países nestes produtos. Dado que as receitas com exportações são resultado das variações da quantidade e dos preços dos produtos exportados, ao se considerar que o progresso técnico do setor de produção de bens primários tende a ser plenamente repassado aos preços finais dos produtos, deste modo, ceteris paribus, o declínio dos preços das commodities tende a reduzir as receitas com exportações do país. Apesar disto, as exportações de recursos naturais poderiam ajudar no processo de industrialização por meio da criação de capacidade de importação de bens intermediários e de capital (Prebisch, 1984; Bielschowsky, 2000; Sinnot; Nash; De la Torre, 2010). 
baixa elasticidade na oferta e na demanda destes bens se transmitiria para os preços, potencialmente mais voláteis, comprometendo a gestão macroeconômica de países cuja renda em geral, e as rendas do setor público, em particular, são fortemente dependentes de pouco setores. Rent-seeking, corrupção e graves problemas de concentração de renda, regimes políticos não democráticos, guerras, instabilidade política e instituições de baixa qualidade seriam recorrências em países altamente dependentes da produção e exportação de commodities (World Bank, 2008; Sinnot, Nash e De la Torre; Black, 2015).

O caráter não renovável de certas commodities, especialmente petróleo e minerais, pode gerar processos de sobre-exploração e de exaustão dos recursos existentes e externalidades negativas como poluição, e exaustão de outros recursos associados (água, ar, solo etc.). Além dos desincentivos gerados pela "doença holandesa", o caráter de enclave físico de sua produção, bem como o fato dos investimentos iniciais para sua obtenção serem muito elevados e de longo retorno de maturação, podem induzir a conflitos de propriedade, redução de investimentos em outros setores da economia, concentração da infraestrutura física e legal para dar sustentação exclusiva tais atividades, etc. A excessiva concentração de investimentos nos setores produtores de commodities poderia implicar, também, na redução nos investimentos em recursos humanos e em setores capital-intensivos reduzindo, no longo prazo, o estoque geral de capital das economias.

Por outro lado, em uma perspectiva mais "otimista", trabalhos recentes têm sugerido que as evidências empíricas e históricas permitem concluir que a "maldição de recursos naturais" não é um destino necessário para os países especializados na produção e exportação de commodities ${ }^{4}$. As economias com tais caraterísticas poderiam se beneficiar pelos ciclos de altas nos preços das commodities, para reduzir suas vulnerabilidades financeiras e acelerar o crescimento. Ademais, políticas adequadas poderiam evitar trajetórias negativas, minimizando os riscos antes mencionados e potencializando a capacidade destas rendas extraordinárias em constituir bases sólidas para o desenvolvimento. No plano fiscal haveria de se ajustar os gastos públicos às flutuações de renda geradas pela volatilidade dos preços das commodities. Vale dizer, dever-se-ia evitar a ampliação de gastos correntes em períodos de bonança e criar fundos de estabilização - mais voltados para objetivos macroeconômicos de curto prazo - e "fundos de riqueza" voltados para a preservação da capacidade de crescimento e diversificação produtiva no longo prazo (World Bank, 2008; Sinnot; Nash; De la Torre, 2010; Ledernan; Maloney, 2010).

(4) Ver referências em Sinnot, Nash e De La Torre (2010). Este autores concluem que: "A key finding of this report is that the weight of econometric evidence and of case studies of the historical record indicate that the "commodity curse" (that natural resource abundance undercuts long-run growth), if it exists at all, is neither strong nor inevitable. The preponderance of the evidence indicates that resource wealth, on average, neither undermines nor disproportionately promotes economic growth. Nor, it seems, is there any "political curse" (that natural resource abundance weakens democratic institutions and fuels large-scale conflict), at least not in LAC"' (p. 57). 
O ciclo recente de variação nos preços das commodities reacendeu tal debate, tanto na fase de alta prolongada - o "superciclo" (Prates, 2007; Black, 2015; IMF, 2015) - quanto em sua desaceleração. Conforme pode ser observado no Gráfico 1, dentre as peculiaridades deste ciclo estão o aumento significativo da volatilidade dos preços e a tendência de elevação dos preços relativos destes produtos. Ao se analisar a evolução dos índices mensais de preços gerais e desagregados nos principais grupos de commodities, entre os anos de 1995 e 2014, particularmente na comparação entre os períodos 1995-2002 e 2003-2014, nota-se: estabilidade dos preços no primeiro período versus forte expansão no segundo período; mudança no comportamento da volatilidade, especialmente no período pós-crise financeira americana; liderança na magnitude do índice dos preços dos alimentos no primeiro versus liderança da magnitude do índice dos metais e energia no segundo período.

Gráfico 1

Índices dos preços das commodities - janeiro de 1995 até dezembro de 2014 - Base $100=2010$.

(A)Subgrupos de Commodities

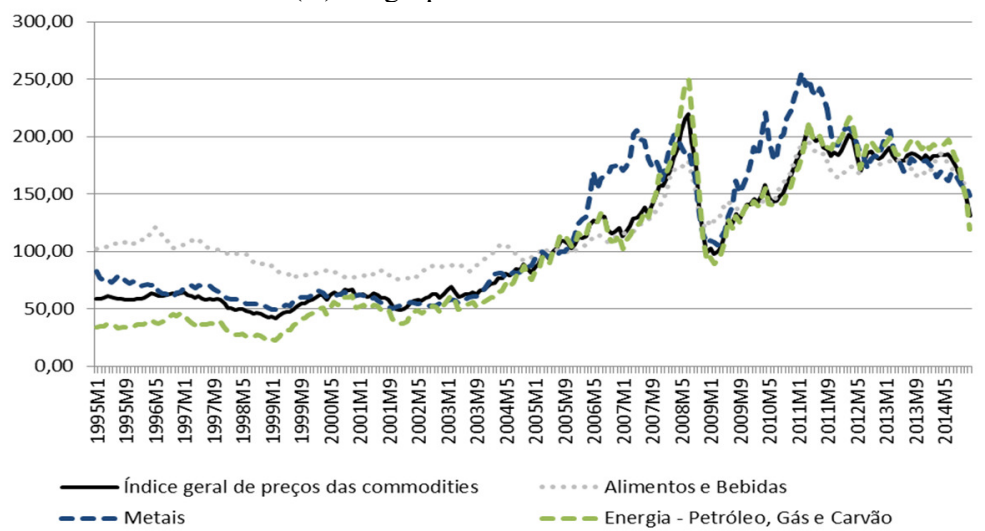

(B) Índices Relativos: Preços de Commodities e de Manufaturas

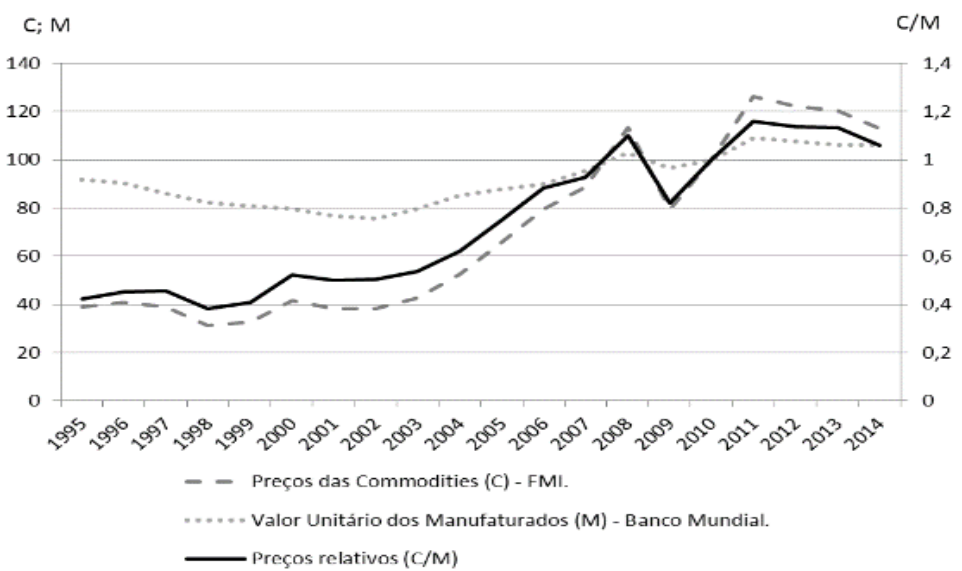

Fonte: Elaboração própria com dados brutos fornecidos pelo FMI e pelo Banco Mundial. 
A associação entre tais movimentos de preços e o desempenho das economias exportadoras e importadoras de recursos naturais ensejou uma profusão de estudos teóricos e empíricos, que buscaram explicar: (i) os determinantes do "superciclo", (ii) seu eventual esgotamento; e (iii) a relação entre alta/baixa e maior/menor dinamismo das economias exportadoras de commodities. Em linhas gerais, as explicações para a dinâmica de preços incluem, com distintas ênfases: as mudanças estruturais na oferta e na demanda globais, com especial atenção dada aos efeitos da ascensão de grandes economias emergentes, particularmente da China; e as consequências da assim chamada "financeirização" dos mercados de commodities. A ampliação na liquidez originada das políticas monetárias expansionistas das economias centrais, a desregulamentação dos mercados e as inovações financeiras, especialmente a proliferação de derivativos, criou a ambiente propício para que tal processo ganhasse força (Prates, 2007; Unctad, 2011; Black, 2015).

Assim, os impactos positivos da alta de preços e, por decorrência, do choque favorável nos termos de intercâmbio, se manifestariam, principalmente: na aceleração do crescimento da renda; na elevação dos investimentos produtivos; na melhoria das condições de solvência e de liquidez externa, na medida em que há influxo de divisas, via exportações e/ou investimentos diretos e de portfólio, permitiria a ampliação dos níveis de reservas internacionais e de geração autônoma de receitas em moedas conversíveis; na ampliação dos níveis de emprego; na melhoria das contas públicas, pelo efeito de elevação na arrecadação de impostos; dentre outros (World Bank, 2008; Sinnot; Nash; De la Torre, 2010; Ledernan; Maloney, 2010; IMF, 2015). Tais efeitos, que se revertem nas fases de baixa, podem ser organizados em termos de canais de transmissão. No presente estudo, enfatizase o "canal externo", de geração de divisas.

No que se refere especificamente ao canal externo de transmissão dos efeitos das variações nos preços das commodities, pode-se destacar, no caso das exportações: (i) efeitos diretos sobre preços e quantidades dos bens exportados, sendo estes recursos naturais; e (ii) efeitos indiretos sobre as exportações de manufaturas, na medida em que se elevam as rendas de terceiros mercados (países exportadores de recursos naturais beneficiados pelo ciclo de alta) que demandam tais produtos (Castilho; Luporini, 2010; Medeiros; Cintra, 2015). Sobre os fluxos de capitais, os modelos "pull and push" desenvolvidos no começo dos anos 1990 para explicar o retorno da poupança externa aos países em desenvolvimento, especialmente na América Latina, sugerem que o fortalecimento dos fundamentos das economias receptoras, dentre eles as condições de solvência e liquidez externa, contribuiriam para "atrair" recursos externos, em suas diversas modalidades (Calvo; Leiderman; Reinhart, 1993; Fernandez-Arias, 1994). Assim, a elevação nas exportações de mercadorias, pelo aumento na demanda global e/ou nos preços, 
implicaria em melhoria na solvência externa, aceleração no crescimento da renda, dentre outros fatores, tornando tais países mais atraentes aos olhos dos investidores internacionais. Portanto, ainda que indiretamente, seria possível associar a alta nos preços dos recursos naturais como sendo uma fonte atratora de capitais estrangeiros.

O "paradigma eclético de Dunning" (1977, 2000), fonte seminal de inspiração para o estudo do IED, apresenta os determinantes dos fluxos de IED e do comportamento das empresas multinacionais (MNE's) no processo de internacionalização da produção. Para Dunning, os fatores que determinam o IED podem ser sintetizados na existência de vantagens de propriedade (ownership advantage - "O"), de localização (location advantage - "L") e de internalização (internalization - "I"), que formam o modelo OLI. Por decorrência, Dunning (2000) afirma haver, basicamente, quatro razões que levam as MNE's a realizarem o IED: orientando-se pela oferta, buscando o acesso a recursos naturais disponíveis no país ou a mão de obra abundante ("resource seeking"); orientando-se pela demanda, cujo objetivo é atender um mercado externo particular ("market seeking"); buscando melhorar a divisão do trabalho de um já existente portfólio de investimentos externos e domésticos da MNE ("efficiency seeking") e; visando proteger ou aumentar as vantagens de propriedade da MNE, bem como reduzir a concorrência ("asset seeking"). Investimentos na exploração de recursos naturais se enquadrariam, tipicamente, na motivação "resource seeking", e um ciclo de alta nos preços das commodities tenderia a ser um determinante direto do IED.

\section{Evidências para o caso do Brasil (2002-2014)}

Para analisar os efeitos do recente período de alta dos preços das commodities (CAPC) sobre a entrada de divisas no Brasil são adotadas duas metodologias econométricas. Por meio dos modelos Markovianos de mudança de regime, busca-se: (i) estimar o período de duração do CAPC; (ii) comparar este com os períodos de estimados para as séries de exportações, IED e IEC, (iii) de modo a verificar se tais períodos são similares. Na sequência, utilizamos modelos de cointegração bivariada e multivariada. A primeira será empregada para verificar a existência de relações estáveis de longo prazo entre os preços das commodities e as séries das exportações, IED e IEC; a segunda investiga, por meio da metodologia econométrica de VAR/VEC, os efeitos dos preços das commodities sobre as exportações, IED e IEC. São estimados três modelos, um para cada agregado e, dentre as variáveis explicativas incluídas em cada modelo, estará o índice de preços das commodities. O Apêndice 1 descreve as variáveis utilizadas nos exercícios econométricos, suas respectivas fontes e as relações teóricas sugeridas pela literatura. 


\subsection{Mudança de Regimes de Markov}

A concepção de que as séries econômicas podem sofrer mudanças estruturais ao longo do tempo vem sendo investigada por diversos autores ${ }^{5}$, que buscam desenvolver métodos para captar estas mudanças de forma endógena. Nesta linha, os modelos de mudança de regime de Markov são amplamente utilizados para investigar o comportamento não linear das séries econômicas, permitindo estimar a duração de cada regime de expansão e de recessão das séries, bem como as probabilidades de transição de um regime para o outro. Em tais modelos, os parâmetros estimados se alteram em função de diferentes regimes estocásticos. Os regimes e os seus turning points não são observados pelo pesquisador (Hamilton, 1990).

No presente estudo, serão testadas duas especificações desta família de modelos: o Markov Switching - Mistura de Normais (MS-MN) e o Markov Switching - Dynamic Regression (MS-DR). O primeiro é a formulação mais básica, onde o processo gerador da variável dependente é formado pela mistura de diferentes distribuições de probabilidades, uma para cada regime não observado estimado endogenamente pelo modelo (Hamilton, 1994). Já o modelo MS-DR pode ser considerado como um desdobramento do modelo de MS-MN, pois adiciona à estimação um componente autorregressivo de ordem $p$ da variável dependente, cujo parâmetro estimado depende das mudanças de regimes não observadas. Nas duas formulações, o ajuste no modelo ocorre instantaneamente com a mudança no regime, ou seja, apresenta uma resposta imediata na série dependente em função das mudanças nos regimes (Doornik, 2013).

Por meio destes modelos pretende-se estimar se houve mudanças de regimes significativas em cada uma das séries de interesse, de modo a verificar se as datas das mudanças mais importantes de cada série são concomitantes. Por meio destes resultados, pode-se escolher o período amostral da pesquisa aqui. A equação 1 fornece a especificação do modelo de MS-MN:

$$
y_{t}=\mu_{s t}+\varepsilon_{t}, \quad \varepsilon_{t} \sim \operatorname{IID}\left(0 ; \sigma^{2}\right)
$$

A equação (1) especifica que o processo gerador da variável observada y, no tempo t, é influenciado pelo intercepto $\mu$, que se modifica de acordo com os diferentes regimes não observados $S$ ao longo do tempo e que podem assumir qualquer valor entre os números naturais, excluindo o zero $(j=1,2, \ldots, N)$. Ademais, $\varepsilon_{t}$ expressa o resíduo da equação.

(5) Tais como Quandt (1972), Goldfeld e Quandt (1973), Dempster, Laird e Rubin (1977), Hamilton (1989; 1990) e Kim (1994).

Economia e Sociedade, Campinas, v. 25, n. 3 (58), p. 695-731, dez. 2016. 
As probabilidades de transição entre os diferentes regimes incluídos no modelo segue uma cadeia de Markov, cuja probabilidade $P$ de o regime $S_{t}$ assumir qualquer valor $j$ depende unicamente do valor $i$ assumido no regime $S_{t-l}$. Segue a distribuição de probabilidade:

$$
P\left(S_{t}=j \mid S_{t-1}=i, S_{t-2}=k, \ldots, y_{t-1}\right)=P\left(S_{t}=j \mid S_{t-1}=i\right)=p_{i j}
$$

Já a equação 3 , modifica a 1 por meio da adição de um vetor da variável dependente defasada $\left(\mathrm{y}_{\mathrm{t}}-1\right)$, cujo parâmetro $\left(\beta_{\mathrm{st}}\right)$ estará sujeito a mudanças de regimes, o que caracteriza o modelo MS-SR.

$$
y_{t}=\mu_{s t}+\beta_{s t} y_{t-1}+\varepsilon_{s t}
$$

A estimação os modelos de MS-MN e MS-DR para cada uma das séries descritas foi realizada por meio do software OxMetrics 7, pacote PcGive 14. A comparação entre os modelos, bem como a escolha do número de regimes incluídos nas regressões, foi realizada com base na análise conjunta dos parâmetros estimados, das estatísticas de ajuste dos resíduos estimados e dos critérios de informação Akaike (AIC) e Schwarz (SC).

O Gráfico 2 apresenta as séries COMM, EXPORT, IEC e IED. A análise prévia das séries que serão sujeitas aos modelos de mudança de regimes é importante, pois conforme afirma Hamilton (1990), a priori, existem apenas suspeitas quanto às possíveis mudanças de comportamento das séries ao longo do tempo. Assim, o possível comportamento estrutural diferenciado ao longo do tempo pode ser observado nas séries e tem-se maior segurança quanto à importância das estimações dos modelos de mudança de regimes.

A análise do Gráfico 2 levanta a suspeita de que tanto os preços das commodities quanto as variáveis representativas da entrada de divisas no Brasil tiveram, de forma concomitante, uma forte mudança de comportamento nos anos 2000. Até o ano de 2004, aparentemente, todas as séries encontravam-se em regime de baixa, com a média das observações 1995-2003 menor do que a média das observações no período entre 2004 e 2014. Assim, a partir de meados da década de 2000, a média, a tendência e a volatilidade de todas as séries parecem ter se alterado significativamente, corroborando assim a importância de verificar se estas mudanças são estatisticamente significativas. Além disto, o comportamento das séries EXPORT e COMM é bastante similar ao longo do tempo, o que já levanta a hipótese da possível existência de uma relação de cointegração entre as duas variáveis. 
Gráfico 2

Comportamento das séries dos preços das commodities, exportações, IED e IEC no Brasil 1995-T1 até 2014-T4

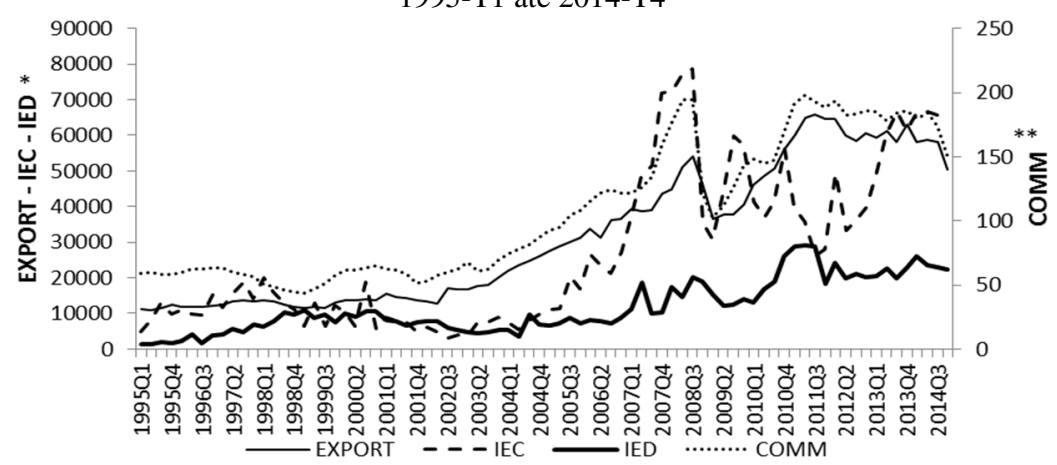

Fonte: Elaboração própria com base nos dados brutos divulgados pelo Banco Central e FMI. *Em milhões de dólares, ajustado sazonalmente. ** Índice de preços das commodities ajustado sazonalmente.

Os resultados dos exercícios sobre mudança de regime estão apresentados no Apêndice 2 (estimativas das duas especificações, as durações dos regimes e as probabilidades de transição de regimes) e no Gráfico 3, que compara as datas de início dos regimes de cada série.

O Gráfico 3 apresenta cada uma das séries observadas e os regimes não observados estimados em cada modelo. As regiões coloridas dos gráficos representam a duração estimada de cada regime e destacam as diferenças existentes na média das séries em cada um dos regimes. Percebe-se, primeiramente, uma elevada proximidade do início do regime de alta dos preços das commodities com o início do regime de alta das exportações do Brasil. Entre 1995 T1 e 2003 T4, os dois regimes de baixa dos preços das commodities se intercalam, sendo que o período é finalizado pelo regime de baixa 1, que é relativamente mais alto do que o regime 3 . Assim, pode-se considerar que a partir de $2002 \mathrm{~T} 2$, quando se inicia o último período estimado para o regime 1 , os preços das commodities já demonstravam sinais de alta, sinais estes que se solidificam a partir de 2004, quando os regimes estimados são evidentemente mais altos em relação aos regimes vigentes no período anterior. Tal movimento se aproxima do comportamento das exportações, posto que o regime de alta da série EXPORT se inicia em 2002 T3, um trimestre à frente do início do regime da alta das COMM. Este já é um forte indício da possibilidade da influência do recente ciclo de alta dos preços das commodities sobre a entrada de divisas no Brasil, via EXPORT, a partir do ano de 2002. 
Gráfico 3

Mudanças de regimes nas séries COMM, EXPORT, IED e IEC - 1995-T1 até 2014-T4
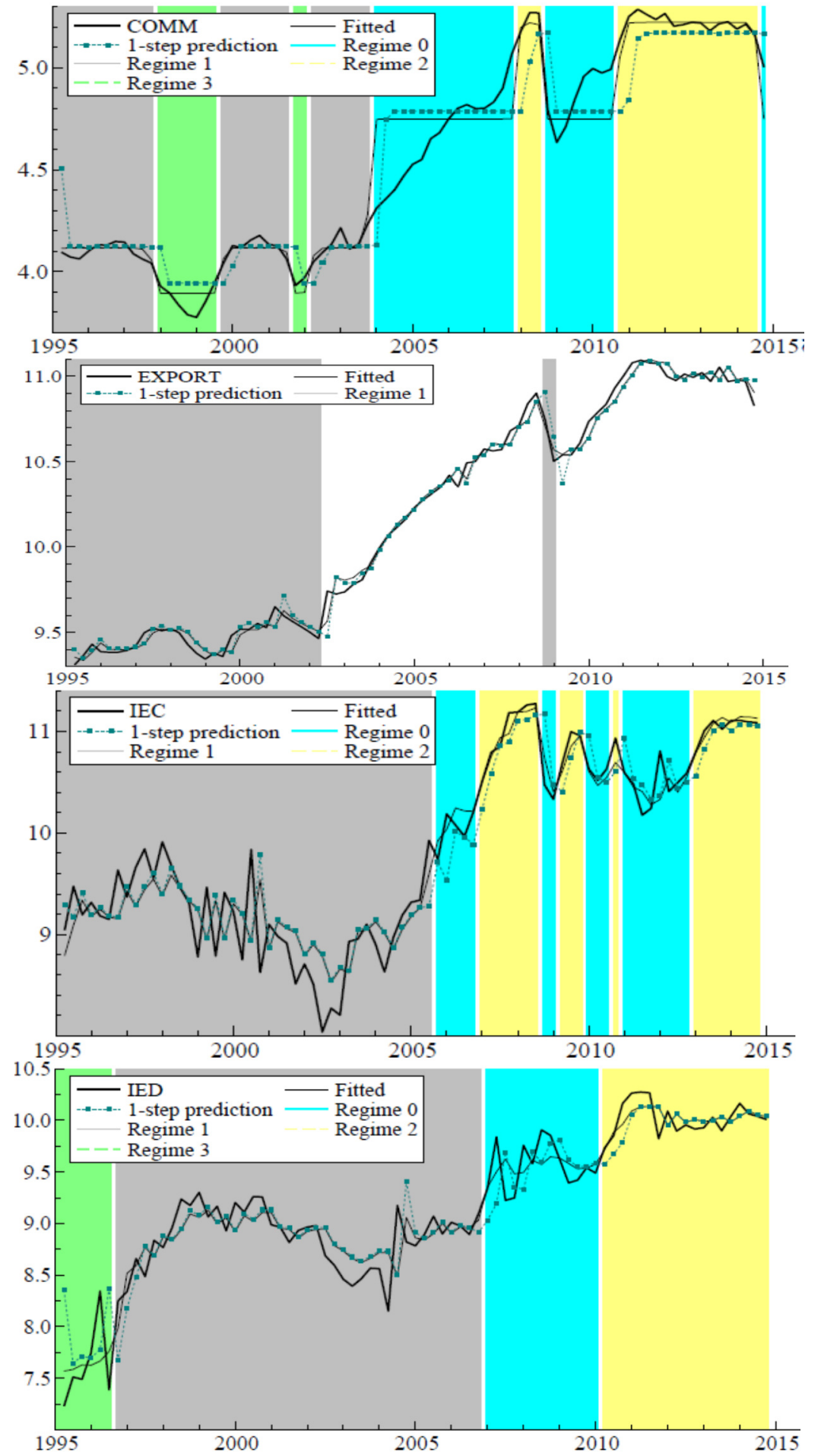

Fonte: Elaboração própria. 
Já as séries do IEC e do IED entram nos seus regimes de alta com uma diferença maior de tempo em relação ao começo da alta dos preços das commodities, sendo que o regime intermediário da série do IEC se inicia em 2005 T2 e a de alta do IED em 2006 T3. Um dos motivos para esta diferença temporal pode residir no efeito dominante dos canais indiretos de transmissão, quais sejam: a melhoria na solvência externa e no nível de atividades a partir do boom das commodities ampliaria, em um segundo momento, a entrada de capitais. No caso das exportações, o canal é direto, por efeitos de preço e quantidade. Ademais, esta diferença pode ter sua origem no próprio comportamento histórico dos preços das commodities, que é bastante volátil e influencia as expectativas futuras destes preços. Em outras palavras, os preços das commodities estavam localizados em um regime de baixa até o ano de 2002, passado certo período de aumento consistente nos preços das commodities, tanto os investidores em carteira quanto os investidores diretos, reformularam suas expectativas em relação aos preços destes produtos, conferindo maior confiança na alta destes preços do que na baixa ou no seu comportamento volátil.

Por fim, cabe ressaltar que a estimação das mudanças de regimes das séries não estabelece, a priori, qualquer relação de causalidade entre as variáveis. $\mathrm{O}$ objetivo, até aqui, era avaliar em que medida houve um movimento conjunto daquelas ao longo de tempo e, concomitantemente, estimar o próprio ciclo de alta dos preços das commodities. Com base nos resultados expostos, definiu-se que o período amostral adotado para esta pesquisa compreende o seguinte intervalo de tempo: 2002-T1 e 2014-T4. Este passa a ser o CAPC em todas as análises realizadas na próxima seção.

\subsection{Análise dos efeitos da alta no preço das commodities: aplicação do VAR/VEC}

Para analisar os efeitos do CAPC sobre a entrada de divisas no Brasil, partese para um segundo conjunto de exercícios por meio da utilização de modelos VAR/VEC. Ao se aplicar tal metodologia e, eventualmente, identificar a existência de um processo de cointegração entre as variáveis envolvidas na análise, sem a necessidade de controlar essas alterações de regimes, pode-se concluir pela existência de uma relação estável entre estas variáveis no longo prazo. Vale dizer, mesmo que os regimes sejam diferentes no curto prazo, nos termos observados pela aplicação do método Markoviano, pode existir uma relação de equilíbrio de longo prazo entre as séries temporais investigadas. Nestes casos, os modelos VAR/VEC tradicionais são eficientes ${ }^{6}$.

(6) A questão da eficiência está associada à comparação entre os graus de liberdade dos modelos VAR com mudança de regime e os mesmos modelos sem o controle dos regimes. Ou seja, a cada regime inserido na especificação econométrica, o número de parâmetros estimados se amplia de forma significativa. 
Isto posto, e após verificar que as séries em tela são integradas em primeira ordem (Apêndice 3), a Tabela 1 revela a existência de relação de cointegração entre as séries EXPORT e COMM; e IED e COMM. Mesmo que, individualmente, estas séries não possuam média e variância constantes, suas respectivas combinações lineares geram relações de equilíbrio de longo prazo. O mesmo não pode ser dito para a relação IEC e COMM.

Tabela 1

Teste de cointegração bivariada Engle-Granger para as séries EXPORT, IEC e IED, contra a série COMM

\begin{tabular}{cc:cccc}
\hline Variável dependente & Lags* & Estatística-tau & P-valor** & Estatística Z & P-valor** \\
\hline \hline EXPORT & 2 & $-4,460$ & 0,004 & $-72,355$ & 0,000 \\
COMM & 2 & $-4,701$ & 0,002 & $-87,892$ & 0,000 \\
\hline IEC & 0 & $-2,422$ & 0,327 & $-11,335$ & 0,251 \\
COMM & 1 & $-2,795$ & 0,185 & $-16,484$ & 0,079 \\
\hline IED & 0 & $-4,339$ & 0,006 & $-25,717$ & 0,007 \\
COMM & 0 & $-4,534$ & 0,003 & $-24,391$ & 0,010 \\
\hline
\end{tabular}

* Escolhido com base no critério de informação Schwarz.**Nível de significância de 5\%.

Fonte: Calculado com o Eviews 9.

Para avançar na compreensão de relações de causalidade, não reveladas pela cointegração bivariada, parte-se para a aplicação dos modelos de cointegração vetorial. Os testes estatísticos usuais para tais exercícios, bem como o resultado da análise de causalidade de Granger, estão reportados no Apêndice 3. O Gráfico 4 e as tabelas 2 e 3 revelam, respectivamente, as funções de resposta ao impulso, as equações de longo prazo e a decomposição da variância. São estimados três modelos econométricos diferentes, onde as séries COMM ou COMM_tx aparecem como variáveis endógenas. Ademais, em cada modelo foram utilizadas variáveis de controle, detalhadas no Apêndice 1. Assim, temos os modelos: (i) exportações: EXPORT*log, Cambio_rlog, PIB_M* $\log , \mathrm{COMM}^{*} \log$; (ii) investimento em carteira: COMM*log, IEC* $\log$, Bovespalog, Joneslog, SELIC, EMBIlog, D_juros, SOL, SOLL, FED, Cambio_nlog, IPCA; (iii) investimento estrangeiro direto: FED, Cambio_nlog, IPCA, IED*log, COMM_tx, PIB*log, AB, AI, PIB_M_tx. Os procedimentos adotados em cada especificação econométrica são semelhantes e seguem, de modo geral, a seguinte ordem: estimativa das estatísticas dos testes de autocorrelação e de heterocedasticidade que, em conjunto com os critérios de informação AIC e SC, definem a escolha do número de defasagens adotadas nos modelos; aplicação dos testes para o número de equações cointegrantes e de causalidade de Granger e; por fim, serão analisados os resultados obtidos na FIR, na equação de longo prazo e na decomposição da variância. Nesta última, a ordem estabelecida para as funções de curto prazo será embasada, primeiramente, nos resultados obtidos no teste de causalidade de Granger e, complementarmente, nos resultados da FIR. 
Gráfico 4

Resultados dos Modelos VAR/VEC

(A) Efeito impulso-resposta sobre a variável EXPORT

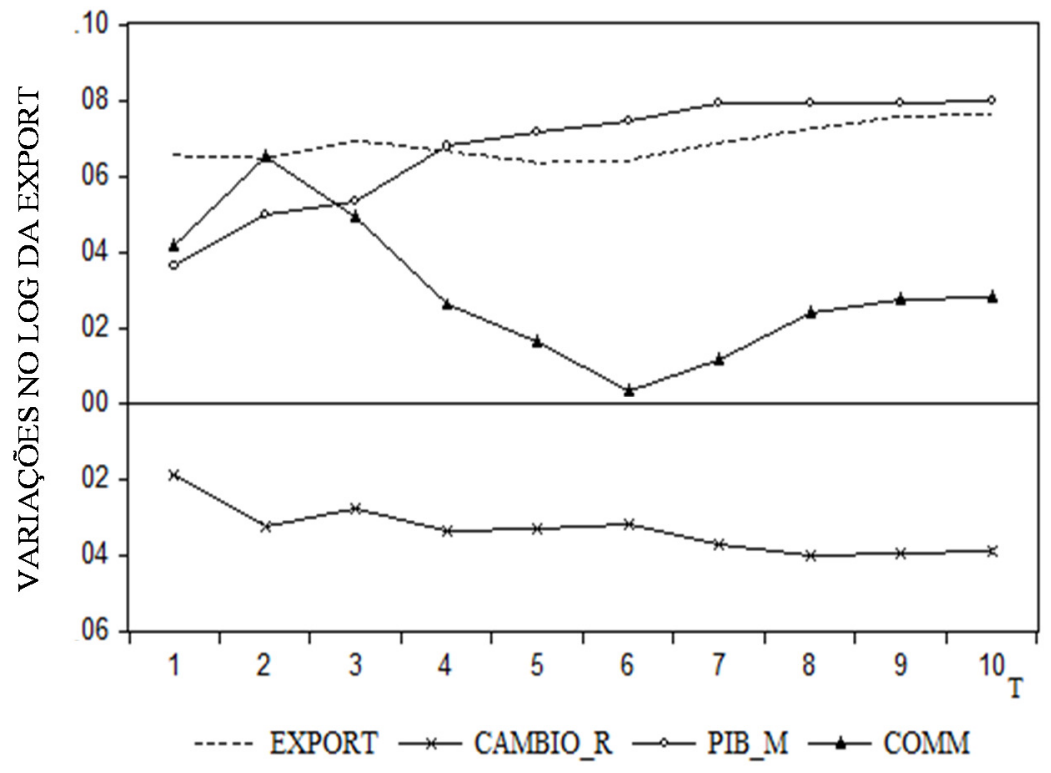

(B) Comportamento das séries EXPORT, PIB_M e COMM e coeficientes de correlação (C)- 1995-T1 até 2014-T4.




(C) Efeito impulso-resposta sobre a variável IEC

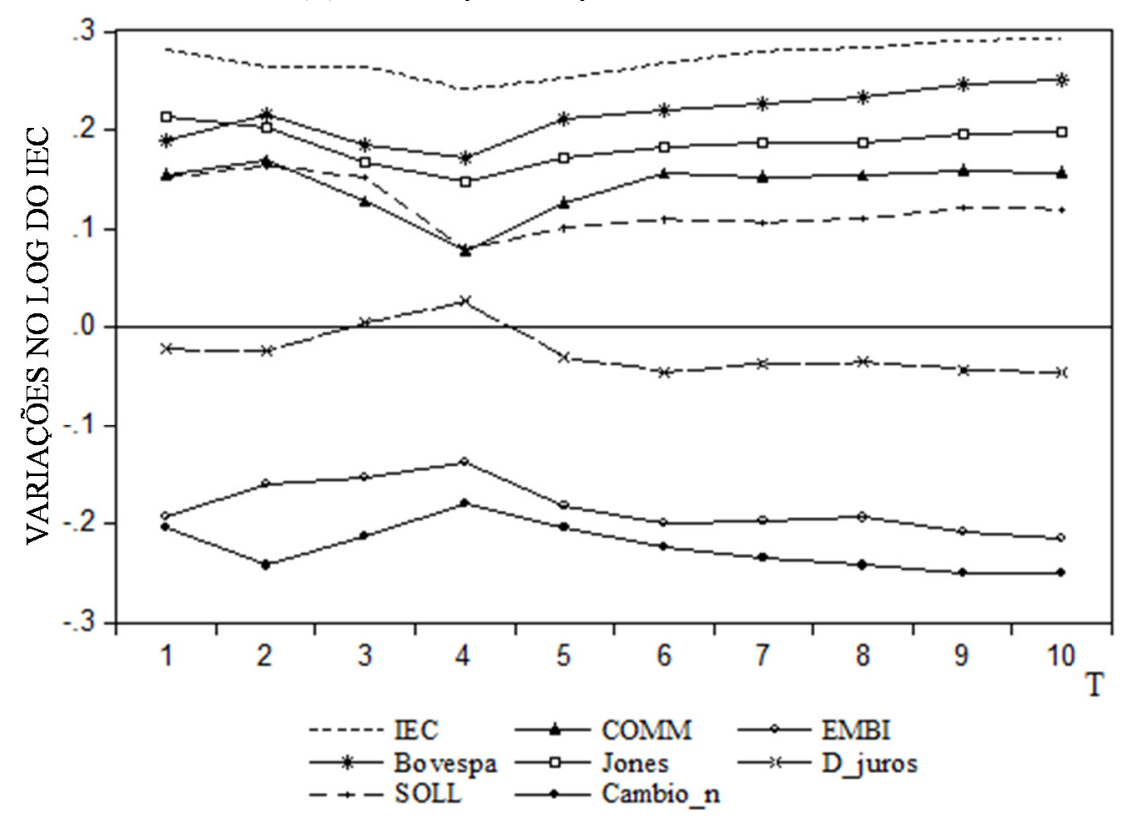

(D) Efeito impulso-resposta sobre a variável IED

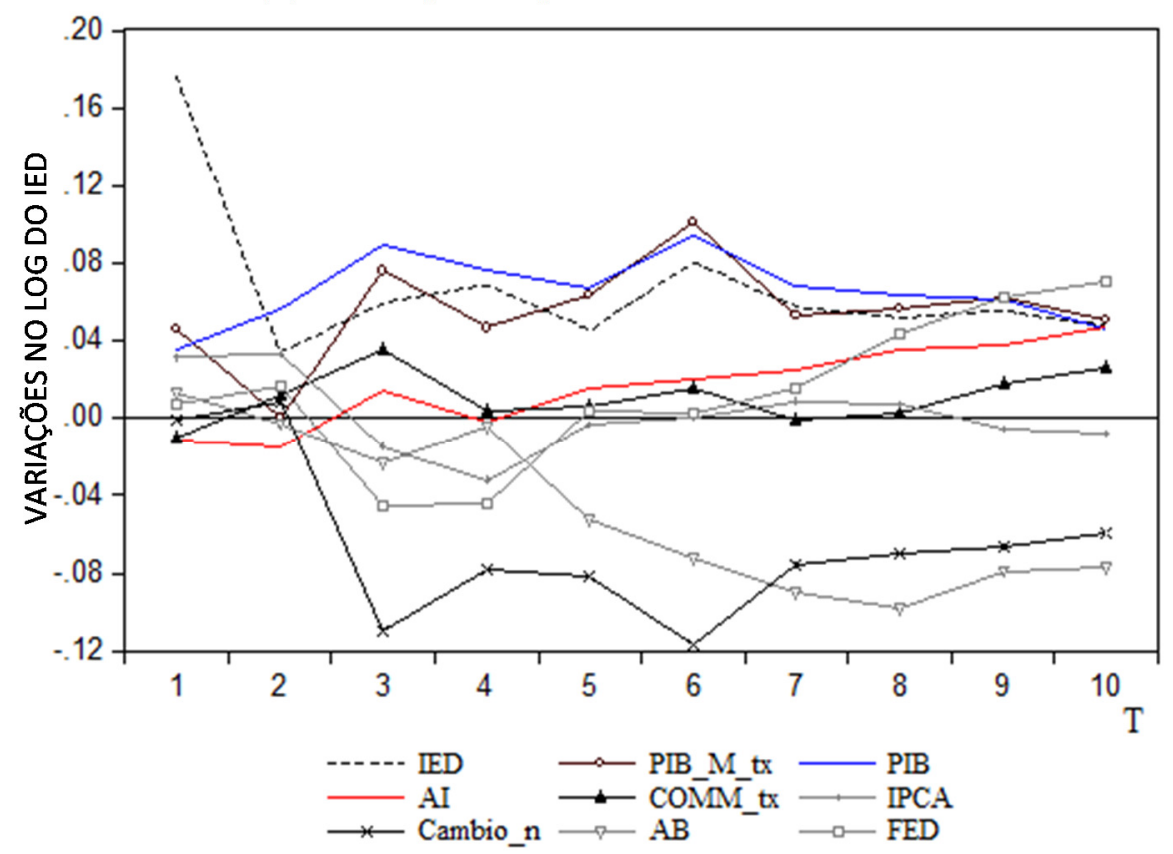

Fonte: Elaboração própria com o Eview 7.0. 
Tabela 2

Equação de longo prazo dos modelos VAR/VEC - 2002-T1 até 2014-T4

\begin{tabular}{|c|c|c|c|c|c|}
\hline \multicolumn{2}{|c|}{ (A) Exportações } & \multicolumn{2}{|c|}{ (B) IEC } & \multicolumn{2}{|c|}{ (C) IED } \\
\hline Variável & $\begin{array}{c}\text { Parâmetro e } \\
\text { desvio padrão }\end{array}$ & Variável & $\begin{array}{c}\text { Parâmetro e } \\
\text { desvio padrão }\end{array}$ & Variável & $\begin{array}{c}\text { Parâmetro e } \\
\text { desvio padrão }\end{array}$ \\
\hline Cambio_r & $0,2141(0,079)$ & COMM & $44,438(6,354)$ & PIB_M_tx & $-0,060(0,164)$ \\
\hline PIB_M & $-3,786(1,038)$ & EMBI & $-20,158(4,874)$ & PIB & $4,410(0,512)$ \\
\hline COMM & $1,548(0,161)$ & Bovespa & $-22,544(5,953)$ & AI & $16,928(5,002)$ \\
\hline Tendência & $0,014(0,003)$ & Jones & $-25,837(8,107)$ & COMM_tx & $0,055(0,007)$ \\
\hline \multirow[t]{5}{*}{ Constante } & 15,817 & D_juros & $8,403(1,134)$ & IPCA & $-0,063(0,024)$ \\
\hline & & SOLL & $-2,400(0,294)$ & Cambio_n & $4,667(0,530)$ \\
\hline & & Cambio_n & $12,650(8,647)$ & $\mathrm{AB}$ & $-0,258(0,041)$ \\
\hline & & $\mathrm{C}$ & 380,86 & FED & $-0,076(0,119)$ \\
\hline & & & & $\mathrm{C}$ & -31.784 \\
\hline
\end{tabular}

Fonte: Elaboração própria com o Eviews 7.

Tabela 3

Decomposição da variância dos modelos VAR/VEC - 2002-T1 até 2014-T4

\begin{tabular}{c|cccc}
\hline \multirow{2}{*}{ Período } & \multicolumn{4}{|c}{ (A) Exportações } \\
\cline { 2 - 5 } & Export & COMM & PIB_M & Cambio_R \\
\hline 1 & 88,93 & 10,02 & 1,03 & 0,02 \\
2 & 90,62 & 6,84 & 2,52 & 0,02 \\
3 & 82,17 & 6,79 & 10,15 & 0,89 \\
4 & 73,64 & 8,33 & 16,58 & 1,44 \\
5 & 64,90 & 12,09 & 20,97 & 2,04 \\
\hline
\end{tabular}

\begin{tabular}{c|cccccccc}
\hline & \multicolumn{10}{|c}{ (B) IEC } \\
\cline { 2 - 9 } Período & IEC & Bovespa & Jones & COMM & Cambio_n & EMBI & SOLL & D_juros \\
\hline 1 & 91,58 & 1,70 & 0,27 & 0,14 & 1,69 & 4,51 & 0,09 & 0,02 \\
2 & 90,78 & 1,19 & 1,79 & 0,25 & 1,63 & 4,04 & 0,29 & 0,03 \\
3 & 88,45 & 0,97 & 2,78 & 1,63 & 1,49 & 3,65 & 0,92 & 0,11 \\
4 & 87,96 & 1,62 & 3,21 & 1,51 & 1,21 & 3,09 & 1,29 & 0,13 \\
5 & 88,06 & 1,96 & 3,51 & 1,25 & 1,01 & 2,58 & 1,53 & 0,11 \\
\hline
\end{tabular}

\begin{tabular}{c|ccccccccc}
\hline & \multicolumn{10}{|c}{ (C) IED } \\
\cline { 2 - 9 } Período & IED & PIB & AI & COMM_tx & PIB_M_tx & IPCA & Cambio_n & AB & FED \\
\hline 1 & 85,30 & 6,98 & 0,04 & 0,07 & 3,38 & 1,22 & 0,24 & 1,87 & 0,89 \\
2 & 55,23 & 13,59 & 3,27 & 0,16 & 3,43 & 2,25 & 8,21 & 3,97 & 9,89 \\
3 & 47,96 & 15,36 & 3,21 & 0,53 & 2,74 & 4,55 & 11,60 & 3,73 & 10,33 \\
4 & 42,05 & 16,34 & 4,25 & 0,72 & 3,84 & 3,92 & 12,20 & 7,73 & 8,95 \\
5 & 35,93 & 16,77 & 5,30 & 0,66 & 5,80 & 3,05 & 12,56 & 12,26 & 7,67 \\
\hline
\end{tabular}

Fonte: Elaboração própria com o Eviews 7. 
Para o caso das exportações, os resultados apresentados no Apêndice 3 sugerem que: (i) a variável EXPORT é determinada endogenamente pelo sistema de equações proposto, uma vez que, a $1 \%$ de significância EXPORT é causada, no sentido de Granger, pelas outras variáveis do modelo; (ii) ao nível de significância de 5\% EXPORT é causada, no sentido de Granger, por COMM e Cambio_r; e (iii) a variável $C O M M$ causa, no sentido de Granger, o $P I B \_M$, resultado que parece ser espúrio. Ao se analisar a FIR, percebe-se a existência de uma elevada sensibilidade da variável EXPORT em relação aos choques ocorridos nas variáveis endógenas do modelo, com destaque para os choques provenientes de $C O M M$ e $P I B \_M$, sendo que esta segunda apresenta o maior efeito positivo sobre as exportações brasileiras, além de resultar em efeitos mais estáveis. As alterações na variância (tabela 3, painel A) corroboram estes resultados, visto que as variáveis $C O M M$ e $P I B \_M$ causam alterações mais significativas na EXPORT, sendo maior o efeito da primeira nos dois primeiros trimestres, passando, a partir do terceiro trimestre, a predominar o efeito da renda mundial sobre as exportações brasileiras. Há, também, um efeito negativo da desvalorização da taxa de câmbio real sobre as exportações, resultado que contradiz a relação de causalidade usual. Em relação aos choques nos preços das commodities, percebe-se um comportamento cíclico mais acentuado na resposta da variável EXPORT, que parece se estabilizar após o oitavo trimestre em um patamar positivo, ou seja, tem-se que os choques na variável COMM influenciam positivamente as exportações brasileiras.

Na equação de longo prazo do modelo VEC (Tabela 2, painel A), as variáveis Cambio_r e COMM influenciam positivamente as exportações brasileiras, sendo que a elasticidade estimada para a segunda variável é significativamente maior do que a estimada para a primeira. A variável $P I B \_M$ apresentou parâmetro estimado negativo e significativo no modelo, o que parece ser um resultado espúrio, pois se espera uma elasticidade-renda da demanda por exportações com sinal positivo. Entretanto, alguns indícios nos levam a considerar que este resultado pode ser fruto de alguma relação muito próxima entre as variáveis $P I B \_M, E X P O R T$ e $C O M M$, que possuem praticamente o mesmo comportamento no período analisado (ver painel B do Gráfico 4).

A partir de 2002, as três séries passaram a apresentar um comportamento bastante similar, com destaque para os movimentos das séries COMM e EXPORT, que foram praticamente iguais, o que resulta em um elevado coeficiente de correlação entre elas, de 0,98. Somente após o ano de 2010 parece ter ocorrido um novo distanciamento da tendência de crescimento das séries $C O M M$ e EXPORT em relação ao observado para a série do $P I B \_M$, a exemplo do que ocorreu entre os anos de 1995 e 2002. Além disto, a divergência na trajetória de crescimento das séries do PIB mundial e das exportações brasileiras, observada após o ano de 2010, pode explicar o sinal negativo estimado para o parâmetro da série $P I B \_M$ no modelo 
VAR/VEC para a série EXPORT. As evidências sugerem que o efeito da série COMM pode estar se sobrepondo aos efeitos da renda mundial sobre a variável EXPORT. O peso crescente das commodities na pauta exportadora brasileira pode ajudar a compreender tal fenômeno. Por decorrência e dados os resultados robustos para a relação entre as exportações e a renda mundial, tanto no teste de causalidade de Granger quanto na FIR, vamos considerar que os resultados para o PIB_M na regressão de longo prazo são apenas não significativos.

Em resumo, os resultados do modelo VEC indicam que os preços das commodities afetam significativamente as exportações brasileiras. Durante o CAPC, um choque positivo na série COMM aumentou significativamente EXPORT no decorrer de dois trimestres, sendo que, após este período, as exportações passaram a apresentar uma resposta mais cíclica ao impulso inicial, que se estabiliza em um patamar positivo, depois de transcorridos oito trimestres. No longo prazo, confirmase, estatisticamente, que o modelo apresenta alguma relação de cointegração e a equação estimada apresentou parâmetro de 1,54 para os preços das commodities, ou seja, um aumento de $1 \%$ nestes preços aumenta em $1,54 \%$ as exportações brasileiras.

Passando à nossa segunda série representativa da entrada de divisas externas, o IEC, observou-se que: (i) apenas a série Bovespa causa, no sentido de Granger, e a 10\% de significância, a variável IEC; (ii) COMM causa, no sentido de Granger, as séries Bovespa, Jones e SOLL, considerando 5\% de significância, sendo que para esta última o sentido de causalidade é bidirecional; (iii) as variações do Bovespa, Jones e EMBI possuem relação expressiva com as mudanças no IEC (ver Tabela 3, painel B). Tal resultado é plausível, pois as ações das grandes empresas exportadoras de commodities são negociadas nas bolsas de valores estadunidense e brasileira e, com isso, aumentos nos preços dos produtos comercializados por elas tende a valorizar os ativos das empresas, o que se reflete em aumento dos respectivos índices bursáteis.

A FIR (Gráfico 4, painel C) sugere que choques no termo errático das equações de determinação das variáveis Bovespa e COMM aumentam, no curto prazo, a entrada de divisas no Brasil via IEC. Choques positivos nas equações das variáveis EMBI e Cambio_n reduzem a entrada de capitais, pois implicam em aumento do risco, no caso da primeira e, aumento da instabilidade da economia, para a segunda. Em relação ao índice Dow Jones, elevações no índice da bolsa estadunidense parecem direcionar capitais rumo à economia brasileira, resultado que pode ser explicado pelo ambiente de ânimo do mercado internacional. Já as respostas de curto prazo apresentadas pelo IEC em relação aos choques nas séries SOLL e $D \_j u r o s$ parecem espúrias, uma vez que as deteriorações nas condições de solvência aumentam o IEC e elevações no diferencial de juros da economia brasileira reduzem o IEC. 
A equação de longo prazo (Tabela 2, painel B) revela uma influência positiva e bastante elevada dos preços das commodities sobre a entrada de IEC no Brasil. Ademais, os parâmetros estimados para as variáveis $E M B I$ e $S O L L$ são negativos e significativos, com $95 \%$ de confiança, mostrando que aumentos no risco e na deterioração das condições de solvência da economia brasileira reduzem a entrada de $I E C$. A taxa de câmbio não apresentou significância estatística para explicar as variações no IEC, no longo prazo. Os resultados encontrados para a variável EMBI vão ao encontro das evidências apresentadas Barbosa e Meurer (2011). Já os resultados encontrados para o indicador de solvência, avançam com relação às pesquisas realizadas por Barbosa e Meurer (2011) e Peres et al. (2013), ao adicionar a variável SOLL na regressão, ao espírito de Calvo, Leiderman e Reinhart (1993) e Fernandez-Arias (1994). Ademais, há uma relação de causalidade bidirecional entre os preços das commodities e a variável SOLL, que pode revelar os efeitos da determinação endógena do indicador de solvência externa das economias receptoras de capital de curto prazo. Tal efeito foi formalizado por Fernandez-Arias (1994), cujo modelo indica que os fatores (push factors) que direcionam os capitais externos em direção às economias em desenvolvimento podem, também, afetar os fatores que atraem estes mesmos capitais para tais economias (pull factors), via indicador de solvência. Os resultados do nosso modelo permitem sugerir que o canal para este efeito indireto, no caso da economia brasileira, durante o período analisado, é alto nos preços das commodities.

Já em relação aos índices das bolsas de valores estadunidense e brasileira, os parâmetros estimados para as variáveis foram negativos e significativos, contrariando os resultados apresentados na FIR. Quanto ao Jones, acredita-se que no longo prazo os agentes irão procurar manter suas inversões vinculadas a ativos mais seguros, emitidos nas economias avançadas. Assim, elevações no índice Dow Jones podem resultar em reduções no IEC do Brasil. Não obstante, no curto prazo os agentes buscam rentabilidade nos mercados de capitais das economias em desenvolvimento. Quanto ao sinal negativo para o índice Bovespa, o resultado parece ser espúrio. A análise conjunta deste resultado e do teste de causalidade de Granger nos leva à seguinte explicação: há um efeito de causação inversa, que inicia com o aumento dos preços das commodities, capazes de "empurrar" capitais externos para a economia brasileira e que resulta em elevação no Ibovespa.

Os resultados do modelo IEC permitem considerar que os preços das commodities parecem ser um importante fator que direciona capital estrangeiro de curto prazo para o Brasil. Este resultado converge com a hipótese de financeirização daqueles preços. A literatura sobre essa questão aponta que a financeirização determinou, de forma essencial, o CAPC país (Prates, 2007; Unctad, 2011; Black, 2015). Com isso, é provável que a alta destes preços tenha contribuído significativamente para a entrada de IEC no Brasil no período em tela. 
No modelo de $I E D$, os testes de causalidade de Granger indicam que: (i) com $10 \%$ de significância, $C O M M \_t x$ e PIB_M_tx causam, no sentido de Granger, as variações no IED brasileiro; (ii) com 5\% de significância, o PIB causa o IED, o que indica a possível importância do tamanho da economia brasileira na entrada de capitais de longo prazo no país. Passando à análise dos efeitos da taxa de crescimento dos preços das commodities, pode-se inferir que: (i) há uma relação de causalidade da variável $C O M M_{-} t x$ para as séries $P I B, A B$ e $P I B \_M \_t x$, sendo que para esta última variável o sentido de causalidade é bilateral; (ii) deste modo, o teste indica que os preços das commodities não só Granger causam o IED, como o PIB causa o IED. A relação entre as séries $C O M M_{-} t x$ e $A B$ não surpreende, visto que o indicador de abertura comercial é formado pela soma das importações e exportações do país, divido pelo PIB. No modelo EXPORT, os preços das commodities influenciam as exportações e, conforme indicado no teste de causalidade de Granger, estes preços causam o PIB.

A FIR (Gráfico 4, painel D) mostra que choques nas variáveis $A I, P I B \_M \_t x$, COMM_tx e PIB geram aumentos na entrada de IED no Brasil. A partir deste resultado e dos obtidos no teste de causalidade de Granger, estabeleceu-se como prioritárias as variáveis representativas do nível de atividade na análise da decomposição da variância (Tabela 3, painel C). Os resultados indicam uma predominância destas variáveis para explicar as mudanças no IED, ficando os preços das commodities com o menor efeito sobre a variável em questão. Aumentos no IPCA, que é uma proxy para a estabilidade econômica do país, geram reduções acentuadas no $I E D$, nos primeiros 5 trimestres após o choque, passando a ter um pequeno efeito positivo a partir do sexto trimestre e voltando a causar efeitos negativos sobre o IED a partir do nono trimestre, resultando, por fim, em um pequeno, mas negativo efeito sobre o IED. As relações de curto prazo com as variáveis $A B$ e $F E D$ são, aparentemente, espúrias, pois choques positivos na primeira geram reduções no $I E D$ e, na segunda, que é uma proxy para a liquidez internacional, geram elevações no $I E D$. Especificamente quanto à série $A B$, aumentos no PIB reduzem o valor do índice de abertura comercial, coeteris paribus; por outro lado, aumentos no PIB atraem investimentos para o Brasil.

A equação de longo prazo (Tabela 2, painel C) mostra que, dentre os resultados significativos, com 95\% de confiança, tem-se que as variáveis ligadas ao nível de atividade econômica do Brasil exercem os maiores efeitos de longo prazo sobre o IED, especialmente a variável $A I$, que representa as oportunidades ligadas ao crescimento do mercado interno do país. Destaca-se, também, que ao longo dos trimestres, as mudanças nesta variável tornam-se substancialmente importantes para explicar as mudanças no IED, o que fica explicito na análise da decomposição da variância. Vale dizer, o IED no Brasil está predominantemente caracterizado como sendo do tipo "market seeking". O Cambio_n apresentou sinal positivo e 
significativo, a 5\% de significância, mostrando que as desvalorizações da moeda nacional aumentam o IED no Brasil, pois reduzem, em dólares, os valores de aquisição dos ativos locais.

O parâmetro estimado para a variável $C O M M_{-} t x$ foi significativo. Apesar de a influência positiva do crescimento dos preços das commodities sobre o IED no Brasil ser pequena, tem-se que estes preços auxiliam no aumento dos investimentos diretos no país. O mesmo ocorre com a variável IPCA, que apresentou parâmetro estimado pequeno, porém significativo e com sinal negativo, mostrando que aumentos na inflação brasileira reduzem a entrada de IED no país. Os resultados estimados para a variável $A B$ são espúrios e os parâmetros estimados para as variáveis $P I B \_M \_t x$ e $F E D$ não são significativos. De modo geral, os parâmetros estimados estão de acordo com os obtidos por UNCTAD (2008), De Castro, Fernandes e Campos (2014), Cunha Junior (2012), dentre outros, na medida em que os preços das commodities exercem influência secundária na determinação do IED destinado ao Brasil.

\section{Considerações finais}

Para avaliar o canal externo de transmissão dos efeitos do ciclo recente de alta nos preços das commodities sobre a economia brasileira, o presente trabalho testou a relação entre aqueles e três agregados do BP: exportações, IEC e IED. Considerando os possíveis efeitos diretos e indiretos pelos quais os preços das commodities podem afetar tais fluxos, foram utilizados modelos econométricos de Mudanças de Regimes Markovianos e de cointergação bivariada e multivariada, o que nos permitiu concluir que aquela alta incrementou a entrada de divisas.

A análise das mudanças de regimes nos preços das commodities indicou o período de crescimento destes preços a partir do ano 2002. Os resultados obtidos permitem notar que durante o ciclo de alta, a duração e a persistência dos regimes da série dos preços das commodities foi maior do que a observada no período anterior ao ano de 2002. Ademais, a partir deste ano, as alternâncias de regimes ocorrem entre os regimes mais altos estimados para o modelo, enquanto que no período entre os anos de 1995 e 2002, a série dos preços das commodities é formada pela alternância dos regimes mais baixos estimados para a série. Esta mesma análise foi estendida para a entrada de divisas no Brasil (exportações, $I E D$ e $I E C$ ), com a obtenção de padrões de comportamento similares aos dos preços das commodities. Tanto a alternância, a persistência e a duração dos regimes foram alteradas após o início do ciclo de alta dos preços das commodities. Com exceção do IED, que apresentou uma alternância de regimes mais estável e gradual, as demais séries seguem padrões de comportamento dos regimes bastante similares, com destaque para os preços das commodities e as exportações, que entram em regimes considerados de alta com apenas um trimestre de diferença. 
A análise Markoviana gerou um primeiro conjunto de informações que autorizam relacionar a expressiva entrada de divisas no Brasil durante os anos 2000, e que possivelmente contribuiu para a acumulação de reservas internacionais ${ }^{7}$ pelo país, com o ciclo de alta dos preços das commodities. Para avançar na compreensão destas relações foram estimados modelos VAR/VEC para as exportações, IED e IEC, com o uso dos preços das commodities como variável explicativa central na análise, acompanhada por variáveis de controle apontadas pela literatura teórica e empírica como importantes na determinação dos fluxos de capitais para economias em desenvolvimento. Os resultados mostram que os preços das commodities foram importantes determinantes da entrada de divisas via exportações e IEC. O efeito sobre o IED foi menor, mostrando que o motivo "resource seeking" de internacionalização da produção de empresas multinacionais possui papel secundário na determinação destes investimentos no Brasil.

No presente estudo não exploramos a provável relação entre aqueles fluxos e a acumulação de reservas internacionais, com efeitos posteriores em indicadores de liquidez e solvência externa, bem como os efeitos das variações nos preços das commodities sobre outros agregados macroeconômicos. Assim, são várias as linhas de investigação a serem exploradas em trabalhos futuros. Se nossas evidências contribuem com a literatura prévia, estão longe de esgotadas as possibilidades de analisar os canais de transmissão dos choques nos preços das commodities e, mais importante, mantém-se em aberto o relevante debate em torno das vantagens e desvantagens da especialização produtiva e comercial, questão que é mais geral, complexa e não pacificada na literatura econômica.

\section{Referências bibliográficas}

BIELSCHOWSKY, R. (Org.). Cinquenta anos de pensamento na Cepal. Rio de Janeiro: Record, 2000.

BLACK, C. Preços das commodities, termos de troca e crescimento econômico brasileiro nos anos 2000. Indicadores Econômicos FEE, v. 42, n. 3, p. 27-44, 2015.

CALDENTEY, E. P.; TITELMAN, D.; CARVALLO, P. Weak expansions: a distinctive feature of the business cycle in Latin America and the Caribbean. New York: The Levy Economics Institute, 2013. (Working Paper, n. 749). Disponível em: www.levy.org.

(7) Cabe ressaltar que a formação de reservas depende, primeiramente, da política cambial adotada pelo país. Dado a adoção de política de câmbio administrada, deve-se ainda considerar os motivos que levam o país a formar reservas. Neste sentido, o estudo de Van Der Laan (2008) investiga quais os principais motivos que levaram o Brasil a adotar esta política de formação de reservas internacionais. Ver, também, World Bank (2008) e IMF (2015). 
CALDERÓN, C.; FUENTES, R. Characterizing the business cycles of emerging economies, policy research. Washington, DC: The World Bank, Jun. 2010. (Working Paper, n. 5343).

CALVO, A. G.; LEIDERMAN, L.; REINHART, C. M. Capital inflows and real exchange rate appreciation in Latin America: the role of external factors. IMF Staff Papers, v. 40, n. 1, 1993.

CASTILHO, R. M.; LUPORINI, V. A elasticidade-renda do comércio regional de produtos manufaturados. Brasília: Cepal-Ipea, 2010. (Textos para Discussão, n. 18).

CUNHA JUNIOR, J. R. A. Determinantes da atratividade de investimentos estrangeiros diretos no Brasil, 2009-2011. 2012. 164f. Tese (Doutorado)Universidade de São Paulo. Faculdade de Economia, Administração e Contabilidade, São Paulo, 2012.

DE CASTRO, P. G.; FERNANDES, E. A.; CAMPO, C. C. Os determinantes do Investimento Externo Direto no Brasil e no México: uma análise empírica. In: ENCONTRO NACIONAL DE ECONOMIA, 41, 2014. Anais... Foz do Iguaçu: ANPEC-Associação Nacional do Centros de Pós-Graduação em Economia, 2014.

DEMPSTER, A. P.; LAIRD, N. M.; RUBIN, D. B. Maximum likelihood estimation from incomplete data via EM algorithm. Journal of the Royal Statistical Society, v. 39, n. 1, p. 1-38, 1977.

DOORNIK, J. A. Econometric analysis with Markov-Switching models - PcGiveTM 14, v. 5.1 ed. London: Timberlake Consultants Ltd., 2013.

DUNNING, J. H. The eclectic paradigm as an envelope for economic and business theories of MNE activity. International Business Review, v. 9, n. 1, p. 163-190, 2000.

DUNNING, J. H. Trade, location of economic activity and the multinational enterprise: a search for an eclectic approach. In: OHLIN, B.; HESSELBORN, P. O.; WIJKMAN, P J. (Org.). The international allocation of economic activity. London: Macmillan, 1977. p. 398-418.

FERNANDEZ-ARIAS, E. The new wave of private capital inflows: push or pull? Washington: World Bank Policy Research, 1994. (Working Paper, n. 1312).

FORNERO, J.; KIRCHNER, M. Learning about commodity cycles and savinginvestment dynamics in a commodity-exporting economy. Santiago: Central Bank of Chile, 2014. (Working Paper, n. 727).

GOLDFELD, S. M.; QUANDT, R. E. A Markov Model for switching regressions. Journal of Econometrics, v. 1, p. 3-16, 1973. 
HAMILTON, J. D. A new approach to the economic analysis of nonstationary time series and the business cycle. Econometrica, v. 57, n. 2, p. 357-384, 1989.

HAMILTON, J. D. Analysis of time series subject to changes in regime. Journal of Econometrics, v. 45, p. 39-70, 1990.

IMF. Western Hemisphere - Regional Economic Outlook. Washington, DC: International Monetary Fund, Apr. 2015.

KALDOR, N. Strategic factors in economic development. New York: Ithaca, 1967.

KIM, Chang-Jin. Dynamic linear models with Markov-switching. Journal of Econometrics, v. 60, p. 1-22, 1994.

MEDEIROS, C.; CINTRA, M. R. V. P. Impacto da ascensão chinesa sobre os países latino-americanos. Revista de Economia Política, v. 35, n. 1, p. 28-42, 2015.

PRATES, D. M. A alta recente dos preços das commodities. Revista de Economia Política, v. 27, n. 3, p. 323-344, 2007.

PREBISCH, R. Five stages in my thinking on development. In MEIER, Gerald M. SEERS, Dudley (Ed.). Pioneers in development. Oxford: Oxford University Press, 1984.

QUANDT, R. E. A New approach to estimating switching regressions. Journal of the American Statistical Association, v. 67, n. 338, p. 306-310, 1972.

REINERT, E. How rich countries got rich and why poor countries stay poor. [s.l.]: Public Affairs, 2007.

SINNOTT, E.; NASH, J.; TORRE, A. Recursos naturais na América Latina: indo além das altas e baixas. 1. ed. Rio de Janeiro: Elsevier, 2010.

SZIRMAI, A. Industrialisation as an engine of growth in developing countries, 1950-2005. Structural Change and Economic Dynamics, v. 23, p. 406-420, 2012.

UNCTAD. World Investment Prospects Survey 2008-2010. New York: United Nations, 2008.

UNCTAD. Trade and Development Report 2011. In: UNITED NATIONS CONFERENCE ON TRADE AND DEVELOPMENT, Geneva, 2011.

UNIDO. Industrial Development Report 2016. The role of technology and innovation in inclusive and sustainable industrial development. Vienna: United Nations Industrial Development Organization, 2016.

UNIDO. Competitive Industrial Performance Report 2012/2013. Vienna: United Nations Industrial Development Organization, 2013. 
VAN DER LAAN, C. Gestão cambial e de fluxos de capitais em economias emergentes: três ensaios sobre a experiência recente do Brasil. Tese (Doutorado em Economia)-Programa de Pós-Graduação em Economia, Faculdade de Ciências Econômicas, Universidade Federal do Rio Grande do Sul, Porto Alegre, 2008.

WHITE, H. Maximum likelihood estimation of misspecified models. Econometrica, v. 50, n. 1, p. 1-25, 1982.

WORLD BANK. Global economic prospects 2009: commodities at the crossroads. Washington, DC: World Bank, 2008.

ZIVOT, Eric; ANDREWS, Donald W. K. Further evidence on the great crash, the oil-price shock, and the unit-root hypothesis. Journal of Business \& Economic Statistics, v. 10, n. 3, p. 251-270, 1992. 


\section{Apêndice 1 \\ Tratamento dos Dados e Fontes}

As séries utilizadas no presente estudo: (i) têm periodicidade trimestral (1995-T1 até 2014-T4); (ii) foram transformadas em número índice, ano base 2000; e (iii) sofreram transformação logarítmica e foram ajustadas sazonalmente pelo método Arima X12.

\section{I) Variáveis de Interesse:}

Preço das Commodities (COMM): Índice geral de preços das commodities, divulgado em periodicidade mensal pelo FMI, ano base 2005. Para este exercício, foi calculada a média de três meses do índice.

Exportações (EXPORT): Exportações de bens Free On Board. Série em milhões de dólares, extraídas do Balanço de Pagamentos brasileiro divulgado pelo Bacen na periodicidade trimestral.

Investimento Estrangeiro em Carteira (IEC): Série em milhões de dólares, extraídas do Balanço de Pagamentos brasileiro divulgado pelo Bacen na periodicidade trimestral.

Investimento Estrangeiro Direto (IED): Série em milhões de dólares, extraídas do Balanço de Pagamentos brasileiro divulgado pelo Bacen na periodicidade trimestral.

\section{II) Variáveis de Controle:}

Taxa de Câmbio Real ${ }_{\text {log }}$ (Cambio_r): Série construída a partir da taxa média de Câmbio nominal (R \$US\$), divulgada pelo Bacen, da taxa de inflação ao consumidor dos EUA, obtida por meio do Bacen, e do Índice Nacional de Preços ao Consumidor Amplo (IPCA), divulgado pelo Instituto Brasileiro de Geografia e Estatística (IBGE). Esta variável será empregada no modelo EXPORT e espera-se que desvalorizações reais na taxa de câmbio do Brasil impulsionem as exportações do país.

Produto Interno Bruto Mundial* ${ }_{\text {log }}$ (PIB_M): Proxy construída a partir da soma do PIB trimestral de 46 países, obtidos na base de dados The Economist Intelligence Unit (EIU), expressos em mil dólares estadunidenses, a preços constantes de 2005, e que representa, em média, 89\% do PIB mundial entre os anos de 2002 e 2014. Pretende-se controlar os efeitos da renda mundial sobre as exportações brasileiras no modelo proposto.

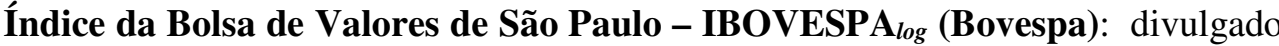
pela BM\&F Bovespa, em periodicidade mensal. Para construir a série trimestral foi calculada a média de três meses do indicador. Esta variável será utilizada no modelo 
do IEC e espera-se que a relação estimada seja positiva, pois incrementos nos valores das ações negociadas na BM\&F podem atrair os capitais de curto prazo para o país. Entretanto, também é possível verificar uma influência positiva do IEC sobre o IBOVESPA, caso a entrada destes capitais seja direcionada para compra de ações que componham o índice.

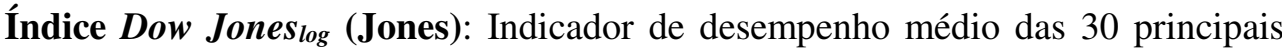
ações negociadas na Bolsa de Valores de Nova Iorque. Os dados brutos foram obtidos por meio do Bacen em periodicidade mensal e, para obter a série trimestral, foi calculada a média de três meses do indicador. Espera-se que o sinal do parâmetro estimado no modelo do IEC seja negativo, pois incrementos no valor das ações da principal bolsa de valores americana devem atrair os capitais para este mercado.

Taxa do Sistema Especial de Liquidação e Custódia (SELIC): Taxa referencial de juros nominal brasileira, divulgada pelo Bacen em periodicidade mensal. Utilizou-se a taxa acumulada de três meses para construir a série trimestral. Esperase que a elevação da taxa de juros básica do Brasil impulsione a entrada de IEC no país.

Emerging Market Bond Index - Risco Brasil ${ }_{\text {log }}$ (EMBI): Índice representativo do spread soberano dos títulos de países em desenvolvimento. Dados obtidos no Instituto de Pesquisa Econômica Aplicada (IPEA) em periodicidade mensal. A série trimestral foi obtida por meio da média de 90 dias. O EMBI - Risco Brasil reflete o risco dos títulos emitidos pelo país em relação aos títulos da dívida americana e será empregado no modelo do IEC.

Federal Funds Rate (FED): Taxa básica de juros nominal overnight do mercado interbancário americano. Série obtida no Bacen, com periodicidade mensal. Utilizou-se a taxa de 3 meses acumulada para construir a série trimestral. Esta variável será utilizada no modelo do IEC, pois se espera que a redução da taxa de juros básica dos EUA empurre os capitais de curto prazo para o Brasil. No modelo do IED, esta variável será utilizada como proxy para a liquidez internacional, verificada especialmente nos anos seguintes ao estouro da crise financeira de 2008 .

Diferencial de taxa de juros (D_juros): Diferença percentual entre a taxa de juros SELIC e a taxa de juros FED. Quanto maior este diferencial, se espera que aumente a entrada de IEC no país.

Solvência - Déficit nas Transações Correntes (DTC) sobre as exportações (SOL): Série percentual construída com base na relação entre o DTC e as exportações de bens Free On Board. A fonte dos dados brutos é o Bacen. Esta variável busca mensurar os efeitos das condições de solvência externa da economia sobre a entrada de IEC no país, visto que a deterioração desta condição resulta em maior percepção de risco por parte dos investidores estrangeiros. 
Solvência - Passivo Externo Líquido (PEL) sobre as exportações - (SOLL): Série percentual construída com base na relação entre o PEL e as exportações de bens Free On Board. A série do PEL foi obtida por meio dos dados brutos do ativo e do passivo externo do Brasil, divulgados pelo Bacen, em periodicidade trimestral, na série histórica da Posição de Investimento Internacional. Esta variável possui o mesmo objetivo da variável SOL no modelo do IEC, entretanto, optou-se por testar as duas especificações de solvência externa e verificar qual delas apresenta as melhores estatísticas de ajuste no modelo. Esta variável parece ser mais relevante no exercício proposto, visto que apresenta a relação entre o tamanho do passivo externo líquido do país em relação à fonte última de divisas externas do país, que são as exportações. Deste modo, espera-se obter uma relação negativa entre esta variável e o IEC. Entretanto, a entrada de IEC no país eleva o PEL, ocasionando, ceteris paribus, uma deterioração do indicador de solvência.

Taxa de Câmbio nominal ${ }_{\text {log }}$ (Cambio_n): Taxa de câmbio nominal (R\$/US\$), divulgada pelo Bacen, em periodicidade trimestral. Para obter a série trimestral, foi realizada a média de três meses. Esta variável será utilizada nos modelos do IEC e do IED e a relação esperada com estes agregados pode ser positiva ou negativa, visto que as desvalorizações da moeda nacional podem gerar incertezas no mercado, reduzir a lucratividade esperada dos investimentos e causar redução na entrada de capitais no país, especialmente no curto prazo. Por outro lado, estas desvalorizações cambiais reduzem os preços dos ativos nacionais em dólares, o que pode impulsionar a entrada de capitais no país em busca de oportunidades de investimentos relacionadas à redução nos custos das inversões.

Produto Interno Bruto do Brasil* ${ }_{\text {log }}$ (PIB): Média móvel de quatro trimestres do PIB brasileiro. Dados brutos obtidos nas Contas Nacionais Trimestrais (CNT) do IBGE, em mil dólares americanos, a preços de 2005. Esta série será utilizada no modelo do IED com o propósito de testar os efeitos do tamanho da economia sobre a entrada de investimentos produtivos no país.

Abertura Comercial (AB): Soma das exportações e importações de bens Free On Board, dividido pelo PIB do país. Dados primários originados no Bacen (séries do BP) e no CNT/IBGE, em milhões de dólares, a preços correntes. Utilizou-se a média móvel de quatro trimestres da série AB. Por fim, espera-se obter uma relação positiva deste indicador com o IED, em linha com o motivo efficiency seeking da teoria do Paradigma Eclético.

Índice Nacional de Preços ao Consumidor Amplo (IPCA): Taxa de inflação oficial brasileira, acumulada dos últimos 12 meses, obtida no IBGE. Proxy utilizada para testar influência da estabilidade econômica do país sobre o IED e IEC.

Taxa de Absorção Interna (AI): Somatório do consumo das famílias, do governo e da Formação Bruta de Capital Fixo do Brasil, dividido pelo PIB do país. As séries 
foram obtidas nas CNT/IBGE trimestrais, a preços correntes, em milhões de reais. Utilizou-se o valor acumulado em 4 trimestres das séries para construir um indicador de médio prazo que possa refletir os efeitos do crescimento do mercado interno sobre a atração de IED para o país. Assim, espera-se que esta variável apresente uma influência positiva sobre o IED, nos termos do motivo market seeking da teoria do Paradigma Eclético.

Taxa de crescimento do PIB mundial (PIB_M_tx): Taxa de crescimento média de quatro trimestres da série PIB_M. Esta variável será utilizada no IED para captar os efeitos do nível de atividade da economia mundial sobre as estratégias de internacionalização da produção das empresas.

Taxa de Crescimento dos Preços das Commodities (COMM_tx): Taxa de crescimento média de quatro trimestres da série COMM. Esta série será aplicada no modelo do IED, em substituição da variável COMM. Esta série será aplicada no modelo do IED. A justificativa para a utilização desta especificação é de que o IED está associado dinâmicas de longo prazo. Logo, é plausível que as empresas tomem decisões a partir do comportamento de médio prazo das variáveis, não se prendendo apenas a mudanças econômicas ocorridas no mesmo momento temporal da decisão de investir. Especificamente em relação aos preços das commodities, Fornero e Kirchner (2014) afirmam que existe um lag temporal entre a alta dos preços das commodities e as decisões empresarias de investir, mesmo em setores voltados a exploração dos recursos naturais. Isto se deve ao caráter de longo prazo destas inversões, que leva os agentes a formularem suas expectativas com base na mudança persistente nos preços das commodities, não com base em choques temporários. Ademais, a pesquisa sobre as intenções de investimentos diretos em economias em desenvolvimento, divulgada pela UNCTAD (2008), está baseada no horizonte temporal de dois anos, o que nos indica que o prazo médio de 1 ano para observação do comportamento dos preços das commodities, por parte dos investidores estrangeiros, parece ser uma alternativa adequada para analisar a influência destes preços sobre os investimentos diretos. 
Apêndice 2

Estimação dos modelos MS-MN e MS-DR

\begin{tabular}{|c|c|c|c|c|c|c|c|c|c|c|c|}
\hline \multicolumn{4}{|c|}{ COMM (2armas) } & \multicolumn{4}{|c|}{ COMM (3ragimes) } & \multicolumn{4}{|c|}{ COMM (4 agmas) } \\
\hline \multicolumn{2}{|c|}{ MS-MN } & \multicolumn{2}{|c|}{ 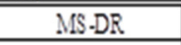 } & \multicolumn{2}{|c|}{ MS-MN } & \multicolumn{2}{|c|}{ MS.DR } & \multicolumn{2}{|c|}{ MS-MA* } & \multicolumn{2}{|c|}{ MS.DR } \\
\hline (0) & $\begin{array}{l}\text { Coef. P-valor } \\
4,99940,0000\end{array}$ & $\begin{array}{l}\text { Cosf. } \\
1,7181\end{array}$ & $\begin{array}{r}\text { P-valor } \\
0,0000\end{array}$ & $\begin{array}{l}\text { Coef. } \\
4,7859\end{array}$ & $\begin{array}{l}\text { P.valor } \\
0,0000\end{array}$ & $\begin{array}{l}\text { Coef: } \\
25927\end{array}$ & $\begin{array}{l}\text { P.ralor } \\
0,2030\end{array}$ & $\begin{array}{l}\text { Conf. } \\
4,7487\end{array}$ & $\begin{array}{l}\text { P.valor } \\
0,0000\end{array}$ & $\begin{array}{l}\text { Coef: } \\
1.9462\end{array}$ & $\begin{array}{l}\text { P.valor } \\
0,0000\end{array}$ \\
\hline (1) & $4,0754 \quad 0,0000$ & $-0,0063$ & 0,9410 & 4,0691 & 0,0000 & $-0,1933$ & 0,0500 & 4,1142 & 0,0000 & 0,2696 & 0,1090 \\
\hline$\mu(2)$ & & & & 5,2238 & 0,0000 & 3,0632 & 0,0000 & 5,2239 & 0,0000 & 3,0116 & 0,0000 \\
\hline (3) & & & & & & & & 3,8929 & 0,0000 & 1,1575 & 0,0000 \\
\hline COMM_l $(0)$ & & 0,5836 & 0,0000 & & & 0,404 & 0,2720 & & & 0,6098 & 0,0000 \\
\hline COMM_1(1) & & 1,0053 & 0,0000 & & & 1,0504 & 0,0000 & & & 0,9505 & 0,0000 \\
\hline COMM_l(2) & & & & & & 0,4140 & 0,0000 & & & 4252 & 0,0000 \\
\hline COMM_1(3) & & & & & & & & & & 0,7103 & 0,0000 \\
\hline Residuo(0) & 0,2492 & 0,0247 & & 0,1883 & & 0,1196 & & 0,2216 & & 0,0489 & \\
\hline Residuo(1) & 0,1342 & 0,0683 & & 0,1271 & & 0,0559 & & 0,0458 & & 0,0270 & \\
\hline Residuo(2) & & & & 0,0381 & & 0,0316 & & 0,0380 & & 0,0306 & \\
\hline \multirow{2}{*}{\multicolumn{4}{|c|}{$\frac{\text { Residuo (3) }}{\text { Teste de Lineandidade }}$}} & & & & & 0,0779 & & 0,0602 & \\
\hline & & & & TestedeI & 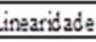 & Teste de L & ineanidade & Testede L & in: & Testa de Li: & mearidade \\
\hline $\mathrm{LR}$ & $\begin{array}{l}\text { Estat. P-valor } \\
150,58 \quad 0,0000\end{array}$ & $\begin{array}{l}\text { Estat. } \\
38865 \\
\end{array}$ & $\begin{array}{r}\text { P-valor } \\
0,0000\end{array}$ & $\begin{array}{l}\text { Estat. } \\
21.2 .1 \\
\end{array}$ & $\begin{array}{l}\text { P.valor } \\
0,0000\end{array}$ & $\begin{array}{l}\text { Estat. } \\
52.108\end{array}$ & $\begin{array}{l}\text { P.ralor } \\
0,0000 \\
\end{array}$ & $\begin{array}{l}\text { Estat. } \\
244,03 \\
\end{array}$ & $\begin{array}{l}\text { P.valor } \\
0,0000\end{array}$ & $\begin{array}{l}\text { Estat. } \\
60.908\end{array}$ & $\begin{array}{l}\text { P.valor } \\
0,0000\end{array}$ \\
\hline \multicolumn{4}{|c|}{ Testes dos Residvos } & Testes do & Residuos & Testes dos & Residvos & \multicolumn{4}{|c|}{ Testes dos Res sivos Testes dos Residvos } \\
\hline & & & $\begin{array}{r}\text { P-valor } \\
02873\end{array}$ & & & $\begin{array}{l}\text { Estat. } \\
1.6629\end{array}$ & & $\begin{array}{l}\text { Es tat. } \\
0,7162\end{array}$ & & $\begin{array}{l}\text { Estat. } \\
0.9952\end{array}$ & $\begin{array}{c}\text { P.valor } \\
0,608\end{array}$ \\
\hline $\mathrm{RCH}$ & $\begin{array}{l}8,480 \\
91,582\end{array}$ & $\begin{array}{l}2,4448 \\
0,0006\end{array}$ & $\begin{array}{l}0,28 / 3 \\
0,9802\end{array}$ & $\begin{array}{l}4,1003 \\
51,4880\end{array}$ & 0,12 & $\begin{array}{l}1,6629 \\
0,0703\end{array}$ & $\begin{array}{l}0,4528 \\
0,7917\end{array}$ & $\begin{array}{l}0,7162 \\
5,2191\end{array}$ & & 922 & $\begin{array}{l}0,008 \\
0,5909\end{array}$ \\
\hline stmenteav & $108.00 \quad 0.0000$ & 20.2000 & 0.0614 & 67.3420 & 0.0000 & 22.018 & 0.0497 & 18.6500 & 0.0973 & 22.147 & 0.0359 \\
\hline \multicolumn{2}{|c|}{ Corténios de selacão } & \multicolumn{2}{|c|}{ Critérios de selação } & \multicolumn{4}{|c|}{ Criténios de seleccio Criterios de selacia } & \multicolumn{4}{|c|}{ Criténios de selacia Critérios de selação } \\
\hline AIC & $-0,3088$ & $-2,3926$ & & $-0,9778$ & & $-2,4599$ & & $.1,2769$ & & $-2,3931$ & \\
\hline & -0.1599 & .2 .1526 & & -0.7098 & & -2.099 & & -0.8998 & & .1 .8233 & \\
\hline \multicolumn{4}{|c|}{ EXPORT (2rezimes) } & \multicolumn{4}{|c|}{ EXPORT (3ragimes) } & \multicolumn{4}{|c|}{ EXPORT (4 rezimes) } \\
\hline \multicolumn{2}{|c|}{ MS $M N$} & $M S$ & & MS & $\mathrm{MN}$ & MS. & & MS. & $\overline{M N}$ & MS. & $\overline{D R}$ \\
\hline (0) & $\begin{array}{c}\text { Coef. P-valot } \\
10,6768 \text { 0,0000 }\end{array}$ & $\begin{array}{l}\text { Cosf. } \\
0,6680\end{array}$ & $\begin{array}{l}\text { P.1210? } \\
0,0040\end{array}$ & $\begin{array}{c}\text { Cosf. } \\
10,4642\end{array}$ & $\begin{array}{l}\text { P.12lor } \\
0,0000\end{array}$ & $\begin{array}{l}\text { Cosf. } \\
0,4557\end{array}$ & $\begin{array}{l}\text { P.12lor } \\
0,1620\end{array}$ & $\begin{array}{l}\text { Coof: } \\
10,6074\end{array}$ & \begin{tabular}{c|} 
P.valor \\
0,0000
\end{tabular} & $\begin{array}{l}\text { Cosf. } \\
0,1551\end{array}$ & $\begin{array}{l}\text { P.ralor } \\
0,4720\end{array}$ \\
\hline (1) & $9,5034 \quad 0,0000$ & 1,303 & 0,0000 & 9,4990 & 0,0000 & 1,2409 & 0,0000 & 9,9844 & 0,0000 & 3,1552 & 0,0000 \\
\hline (2) & & & & 109983 & 0,0000 & 5,4332 & 0,000 & 10,9998 & 0,0000 & 5,7330 & 0,0510 \\
\hline (3) & & & & & & & & 9,4589 & 0,0000 & 1,8655 & 0,0490 \\
\hline XPORT_10 & & 0,9402 & 0000 & & & 0,9640 & 0,0000 & & & 1,0202 & 0,0000 \\
\hline XPORT_1(1 & & 0,8507 & 0000 & & & 0,8692 & 0,000 & & & 0,6445 & 0,0000 \\
\hline EXPORT_le & & & & & & 0,5056 & 0,000 & & & 0,4790 & 0,0720 \\
\hline EXPORT_13 & & & & & & & & & & 0,8032 & 0,0000 \\
\hline Resićvo(0) & 0,3299 & $0,0.955$ & & 0,2711 & & 0,0673 & & 0,1609 & & 0,0383 & \\
\hline Residvo(1) & 0,1345 & 0,0461 & & 0,1294 & & 0,0471 & & 0,2107 & & 0,0674 & \\
\hline Residuo(2) & & & & 0,0674 & & 0,0347 & & 0,0659 & & 0,0377 & \\
\hline Residvo(3) & & & & & & & & 0.0850 & & 0.0455 & \\
\hline Testede I & Lineand ade & Teateda $\mathrm{L}$ & neandade & Teate de I & inaridade & Testede L & ineanidade & Teatede I & ineanidadal & Testede Li: & inaridade \\
\hline IR & $\begin{array}{ll}\text { Estat. P-valot } \\
160.08 & 0.0000\end{array}$ & $\begin{array}{l}\text { Estat. } \\
17.318\end{array}$ & $\begin{array}{l}\text { P.1210 } \\
0.0039\end{array}$ & $\begin{array}{l}\text { Estat. } \\
220.58\end{array}$ & $\begin{array}{l}\text { P.12lor } \\
0.0000\end{array}$ & $\begin{array}{l}\text { Estat. } \\
22.272\end{array}$ & $\begin{array}{c}\text { P.ralor } \\
0.0081\end{array}$ & $\begin{array}{l}\text { Etat. } \\
261.15\end{array}$ & $\begin{array}{l}\text { P.valor } \\
0.0000\end{array}$ & $\begin{array}{l}\text { Etat. } \\
41.925\end{array}$ & $\begin{array}{l}\text { P.ralor } \\
0.0001\end{array}$ \\
\hline Testes & os Residvos & Testes dos & Residuos & Cestes do & Residvosi & estes dos & Residvos & Costes dos & Residuos & Testes dos & Residvos \\
\hline & Estat. P.valor & Estat. & P.ralor & Estat. & P-ralor & Es tat. & P.ralor & Etat. & P.valor & Estat. & Pralor \\
\hline omalidad & $2,132 \quad 0,3444$ & 4,6679 & 0,0969 & 0,0077 & 0,99 & 7,3590 & 0,052 & 0,1137 & & 93 & 0,1219 \\
\hline $\mathrm{ARCH}$ & $99,0890,0000$ & 0,3731 & 0,5422 & 23,003 & 0,0000 & 0,085 & 0,4030 & 6,5095 & 0,0130 & 0.2006 & 0,6558 \\
\hline Bortmantea' & $130.420 \quad 0.0000$ & 10.4490 & 0.5766 & 66.224 & 0.0000 & 12.349 & 0.48 .8 & 93.7090 & 0.0000 & 14.9 & 0.2464 \\
\hline Cintérios & deselacia & Critátios d & A seleczão & Critánios & Aselacia & Critánios d & A selacian & Critátios d & A selaczão & Cattenios d & A selaciz \\
\hline IIC & 0,0655 & $-2,4628$ & & $-0,6157$ & & $-2,4242$ & & $-1,0477$ & & $-2,5464$ & \\
\hline 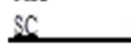 & 0.2144 & .2 .2228 & & -0.3775 & & .20643 & & -0.7202 & & 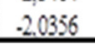 & \\
\hline
\end{tabular}


Sabrina Monique Schenato Bredow, Marcos Tadeu Caputi Lélis, André Moreira Cunha

\begin{tabular}{|c|c|c|c|c|c|c|c|c|c|c|c|}
\hline \multicolumn{4}{|c|}{$\operatorname{IEC}$ (2 regimes) } & \multicolumn{4}{|c|}{$\operatorname{IEC}$ (3 regimes) } & \multicolumn{4}{|c|}{$\operatorname{IEC}$ (4 regimes) } \\
\hline \multicolumn{2}{|c|}{ MS-MN } & \multicolumn{2}{|c|}{ MS-DR } & \multicolumn{2}{|c|}{ MS-MN } & \multicolumn{2}{|c|}{ MS-DR } & \multicolumn{2}{|c|}{ MS-MN } & \multicolumn{2}{|c|}{ MS-DR } \\
\hline & Coef. P-valor & $\begin{array}{l}\text { Coef. } \\
10415\end{array}$ & P-valor & $\begin{array}{l}\text { Coef. } \\
10526\end{array}$ & P-valor & Coef. & P-valor & $\begin{array}{c}\text { Coef. } \\
\end{array}$ & P-valor & $\begin{array}{l}\text { Coef. } \\
31630\end{array}$ & $\begin{array}{l}\text { P-valor } \\
\text { nato }\end{array}$ \\
\hline $\begin{array}{l}\mu(0) \\
\mu(1)\end{array}$ & $10,724 \quad 0,0000$ & 1,9845 & 0,2400 & 10,5362 & 0,0000 & & 0,0090 & $\begin{array}{r}10,5429 \\
93878\end{array}$ & 0,0000 & $\begin{array}{l}3,1630 \\
56526\end{array}$ & $\begin{array}{l}0,0400 \\
0,0000\end{array}$ \\
\hline$\mu(1)$ & $9,1354 \quad 0,0000$ & 4,1605 & 0,0020 & 9,1259 & 0,0000 & 3,9731 & 0,0170 & 9,3878 & 0,0000 & 5,6526 & 0,0000 \\
\hline$\mu(2)$ & & & & 11,1295 & 0,0000 & 4,0495 & 0,1150 & 11,1296 & 0,0000 & 3,4357 & 0,0010 \\
\hline$\mu(3)$ & & & & & & & & 8,7135 & 0,0000 & 6,4389 & 0,0020 \\
\hline IEC_1 $1(0)$ & & 0,8162 & 0,0000 & & & 0,4193 & 0,0560 & & & 0,6918 & 0,0000 \\
\hline IEC_1(1) & & 0,5435 & 0,0000 & & & 0,5661 & 0,0030 & & & 0,4047 & 0,0000 \\
\hline IEC_1(2) & & & & & & 0,6387 & 0,0070 & & & 0,6944 & 0,0000 \\
\hline IEC_1(3) & & & & & & & & & & 0,2741 & 0,2140 \\
\hline Resíduo(0) & 0,3599 & 0,2426 & & 0,2856 & & 0,2177 & & 0,2804 & & 0,2592 & \\
\hline Resíduo(1) & 0,4763 & 0,3839 & & 0,4691 & & 0,3770 & & 0,3487 & & 0,2152 & \\
\hline Resíduo(2) & & & & 0,0835 & & 0,0877 & & 0,0835 & & 0,0883 & \\
\hline Resíduo(3) & & & & & & & & 0,3319 & & 0,3966 & \\
\hline
\end{tabular}

\begin{tabular}{c|c|c|c|}
\hline Teste de Linearidade & Teste de Linearidade & Teste de Linearidade Teste de Linearidade Teste de Linearidade Teste de Linearidade \\
\hline
\end{tabular} $\begin{array}{lllllllllll}\text { Estat. P-valor } & \text { Estat. } & \text { P-valor } & \text { Estat. } & \text { P-valor } & \text { Estat. } & \text { P-valor } & \text { Estat. } & \text { P-valor } & \text { Estat. } & \text { P-valor }\end{array}$ \begin{tabular}{lllllllllllll} 
LR & 112,82 & 0,0000 & 17,171 & 0,0018 & 137,84 & 0,0000 & 31,779 & 0,0002 & 154,69 & 0,0000 & 40,954 & 0,0001 \\
\hline
\end{tabular}

\begin{tabular}{|c|c|c|c|c|c|c|c|c|c|c|c|}
\hline \multicolumn{2}{|c|}{ Testes dos Resíduos } & \multicolumn{2}{|c|}{ Testes dos Resíduos } & \multicolumn{4}{|c|}{ Testes dos Resíduos Testes dos Resíduos } & \multicolumn{4}{|c|}{ Testes dos ResíduosiTestes dos Resíduos } \\
\hline & Estat. P-valor & Estat. & P-valor & Estat. & P-valor & Estat. & P-valor & Estat. & P-valor & Estat. & P-valor \\
\hline Normalidade & $3,294 \quad 0,1927$ & 1,6270 & 0,4433 & 1,5120 & 0,4695 & 1,9385 & 0,3794 & 1,3905 & 0,4989 & 5,435 & 0,0660 \\
\hline $\mathrm{ARCH}$ & $17,5290,0001$ & 0,7535 & 0,3883 & 10,853 & 0,0016 & 1,3418 & 0,2510 & 0,6665 & 0,4172 & 0,4906 & 0,4863 \\
\hline Itmanteau & $55,0990,0000$ & 22,0380 & 0,0371 & 44,239 & 0,0000 & 26,179 & 0,1010 & 23,4360 & 0,0242 & 21,988 & 0,0377 \\
\hline \multicolumn{2}{|c|}{ Critérios de seleção } & \multicolumn{2}{|c|}{ Critérios de seleção } & \multicolumn{2}{|c|}{\begin{tabular}{|l|} 
Critérios de seleção \\
\end{tabular}} & \multicolumn{2}{|c|}{ Critérios de seleção } & \multicolumn{2}{|c|}{ Critérios de seleção } & \multicolumn{2}{|c|}{ Critérios de seleção } \\
\hline AIC & 1,3375 & \multirow{2}{*}{\multicolumn{2}{|c|}{$\begin{array}{l}0,7152 \\
0,9251\end{array}$}} & \multirow{2}{*}{\multicolumn{2}{|c|}{$\begin{array}{ll}1,1247 \\
1,3926\end{array}$}} & \multirow{2}{*}{\multicolumn{2}{|c|}{$\begin{array}{l}0,6569 \\
1,0168\end{array}$}} & \multirow{2}{*}{\multicolumn{2}{|c|}{$\begin{array}{l}1,0140 \\
1,4011 \\
\end{array}$}} & \multirow{2}{*}{\multicolumn{2}{|c|}{$\begin{array}{l}0,6420 \\
1,1219\end{array}$}} \\
\hline 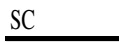 & 1,4863 & & & & & & & & & & \\
\hline \multicolumn{4}{|c|}{$\mathbb{E D}$ (2asimas) } & \multicolumn{4}{|c|}{$\mathbb{E D}$ (3erimes) } & \multicolumn{4}{|c|}{ IED (4raimes) } \\
\hline \multicolumn{2}{|c|}{$\mathrm{MN}$} & \multicolumn{2}{|c|}{ MS.DR } & \multicolumn{2}{|c|}{$\mathrm{MN}$} & \multicolumn{2}{|c|}{ MS.DR } & \multicolumn{2}{|c|}{$\mathrm{MN}$} & \multicolumn{2}{|c|}{ MS.DR* } \\
\hline & Coef. P-ralos & Coef. & P.valor & Coef. & P.valor & Cosf. & P.valor & Coef. & P-valor & Coef. & P.ralor \\
\hline (0) & 0,0000 & 59527 & 0,0090 & 9,0203 & 0,0000 & 7,2610 & 0,0160 & 9,5756 & 0,0000 & 73674 & 0,0070 \\
\hline 1) & 0,0000 & 1,5241 & 0,0080 & 8,1359 & 0,0000 & 1,9370 & 0,0040 & 8,8802 & 0,0000 & 3,9328 & 0,0000 \\
\hline 2) & & & & 9,8403 & 0,0000 & 6,0153 & 0,0030 & 10,0398 & 0,0000 & 5,9925 & 0,0080 \\
\hline 3) & & & & & & & & 7,6733 & 0,0000 & 6,4574 & 0,0090 \\
\hline D_1(0) & & 0,4069 & 0,0700 & & & 0,2420 & 0,4330 & & & 0,2301 & 0,4150 \\
\hline D_(1) & & 0,8327 & 0,0000 & & & 0,7819 & 0,0000 & & & 0,5586 & 0,0000 \\
\hline D_.1(2) & & & & & & 0,4009 & 0,0430 & & & 0,4032 & 0,0700 \\
\hline$D_{-} 1(3)$ & & & & & & & & & & 0,1559 & 0,6120 \\
\hline sidvo(0) & 0,2751 & 0,1287 & & 0,1618 & & 0,2114 & & 0,2240 & & 0,2217 & \\
\hline siduo(1) & 0,5658 & 0,2862 & & 0,5229 & & 0,2856 & & 0,2799 & & 0,2160 & \\
\hline siduo(2) & & & & 0.2891 & & 0,1306 & & 0,1399 & & 0,1306 & \\
\hline sidvo(3) & & & & & & & & 0.4430 & & 0.3670 & \\
\hline & & & & & & & & Teste deI & & ate deI & 502 \\
\hline LR & $\begin{array}{c}\text { Etat. P-izlo } \\
77,7080.0000\end{array}$ & $\begin{array}{l}\text { Etat. } \\
9.6263\end{array}$ & $\begin{array}{l}\text { P.valor } \\
0.0472\end{array}$ & $\begin{array}{l}\text { Estat. } \\
135,36 \\
\end{array}$ & $\begin{array}{l}\text { P.valor } \\
0.0000\end{array}$ & $\begin{array}{l}\text { Estat. } \\
13.536 \\
\end{array}$ & $\begin{array}{l}\text { P.yalor } \\
0.0947\end{array}$ & $\begin{array}{l}\text { Estat. } \\
158.72\end{array}$ & $\begin{array}{l}\text { P.valor } \\
0.0000\end{array}$ & $\begin{array}{l}\text { Estat. } \\
26.119\end{array}$ & $\begin{array}{l}\text { P.12lor } \\
0.0103\end{array}$ \\
\hline \multicolumn{4}{|c|}{ Testas dos Rasidvos } & \multicolumn{4}{|c|}{ Tastas dos RasidvosiTastas dos Rasidvos } & \multicolumn{4}{|c|}{ Testas dos RasivivosiTestas dos Residvos } \\
\hline & Estat. P-ralod & Estat. & P.valor & Estat. & P-valor & Estat. & P.valor & Es tat. & P.valor & Estat. & P.ralor \\
\hline malidade & & 19 & 0,0001 & 4,6235 & 0,0991 & 18,3720 & 0,0001 & 1,0438 & 0,5934 & 3,5823 & 0,1668 \\
\hline $\mathrm{ARCH}$ & $71,3870,0000$ & 5,0078 & 0,0284 & 7,216 & 0,0090 & 3,6996 & 0,0587 & 7,8441 & 0,0067 & 8,4797 & 0,0050 \\
\hline tmanteay & $121.23 \quad 0.0000$ & 22.895 & 0.0286 & 40.858 & 0.0001 & 21.150 & 0.0482 & 29.2050 & 0.0037 & 19.256 & 0.0825 \\
\hline Caténios & deselacia & Cateinos d & elaça & Critérios & 3atacio & Criténios d & a selaçà & Criténios & selagca & Criterios & 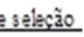 \\
\hline ic & 1.3 & 0,2596 & & 0,7652 & & 0,3114 & & 0,5233 & & 0,2534 & \\
\hline & 1.5348 & 0.4696 & & 1.0332 & & 0.6413 & & 0.8508 & & 0.70 & \\
\hline
\end{tabular}

* Modelos estimados com resíduos robustos. ** Todos os testes estatísticos levaram em consideração o nível de significância de 5\%. 
Duração e Transição dos Regimes -

(*) Parâmetros estatisticamente significativos a 5\% de significância

Duração dos Regimes - Modelo MS-MN(4) para a série COMM - 1995-T1 até 2014-T4

\begin{tabular}{|c|c|c|c|c|}
\hline & Parâmetro & Data de início & Data final & Trimestres de duração \\
\hline REGIME 0 & $4,7487 *$ & $\begin{array}{l}\text { 2004-T1 } \\
\text { 2008-T4 } \\
\text { 2014-T4 }\end{array}$ & $\begin{array}{l}2007-\mathrm{T} 4 \\
\text { 2010-T3 } \\
\text { 2014-T4 }\end{array}$ & $\begin{array}{l}16 \\
8 \\
1\end{array}$ \\
\hline REGIME 1 & $4,1142 *$ & $\begin{array}{l}1995-\mathrm{T} 1 \\
1999-\mathrm{T} 4 \\
2002-\mathrm{T} 2\end{array}$ & $\begin{array}{l}1997-\mathrm{T} 4 \\
2001-\mathrm{T3} \\
\text { 2003-T4 }\end{array}$ & $\begin{array}{c}12 \\
8 \\
7\end{array}$ \\
\hline REGIME 2 & $5,2239 *$ & $\begin{array}{l}2008-\mathrm{T} 1 \\
2010-\mathrm{T} 4\end{array}$ & $\begin{array}{l}2008-\mathrm{T} 3 \\
2014-\mathrm{T} 3\end{array}$ & $\begin{array}{c}3 \\
16\end{array}$ \\
\hline REGIME 3 & $3,8929 *$ & $\begin{array}{l}1998-\mathrm{T} 1 \\
2001-\mathrm{T} 4\end{array}$ & $\begin{array}{l}\text { 1999-T3 } \\
2002-\mathrm{T} 1\end{array}$ & $\begin{array}{l}7 \\
2\end{array}$ \\
\hline
\end{tabular}

Duração dos Regimes - Modelo MS-DR(2) para a série EXPORT - 1995-T1 até 2014-T4

\begin{tabular}{c|c|ccc}
\hline & Parâmetro & Data de início & Data final & Trimestres de duração \\
\hline \hline \multirow{2}{*}{ REGIME 0 } & $\mu: 0,668^{*}$ & 2002-T3 & 2008-T3 & 25 \\
& Export_1: 0,9402* & 2009-T2 & 2014-T4 & 23 \\
\multirow{2}{*}{ REGIME 1 1} & $\mu: 1,3303^{*}$ & $1995-T 1$ & 2002-T2 & 29 \\
& Export_1:0,8597* & 2008-T4 & 2009-T1 & 2 \\
\hline
\end{tabular}

Duração dos Regimes - Modelo MS-DR(3) para a série IEC - 1995-T1 até 2014-T4

\begin{tabular}{c:c:ccc}
\hline & Parâmetro & Data de início Data final Trimestres de duração \\
\hline \hline REGIME & $\mu: 6,0114^{*}$ & 2004-T1 & 2007-T4 & 16 \\
0 & IEC_1: 0,4193* & 2008-T4 & 2010-T3 & 8 \\
& & $2014-\mathrm{T} 4$ & $2014-\mathrm{T} 4$ & 1 \\
REGIME & $\mu: 3,9731^{*}$ & $1995-\mathrm{T} 1$ & $1997-\mathrm{T} 4$ & 12 \\
1 & IEC_1: $0,5661^{*}$ & $1999-\mathrm{T} 4$ & $2001-\mathrm{T} 3$ & 8 \\
& & $2002-\mathrm{T} 2$ & $2003-\mathrm{T} 4$ & 7 \\
REGIME & $\mu: 4,0495^{*}$ & 2008-T1 & 2008-T3 & 3 \\
2 & IEC_1: 0,6387* & 2010-T4 & 2014-T3 & 16 \\
\hline
\end{tabular}

Duração dos Regimes - modelo MS-DR(4) para a série IED - 1995-T1 até 2014-T4

\begin{tabular}{|c|c|c|c|c|}
\hline & Parâmetro & Data de início & Data final & Trimestres de duração \\
\hline $\begin{array}{c}\text { REGIME } \\
0\end{array}$ & $\begin{array}{c}\mu: 7,3674^{*} \\
\text { IED_1: } 0,2301\end{array}$ & 2007-T1 & 2010-T1 & 13 \\
\hline $\begin{array}{c}\text { REGIME } \\
1\end{array}$ & $\begin{array}{c}\mu: 3,9328^{*} \\
\text { IED_1: } 0.5586^{*}\end{array}$ & 1996-T4 & 2006-T4 & 41 \\
\hline $\begin{array}{c}\text { REGIME } \\
2\end{array}$ & $\begin{array}{c}\mu: 5,9925^{*} \\
\text { IED_1: } 0,4032^{*}\end{array}$ & 2010-T2 & 2014-T4 & 19 \\
\hline $\begin{array}{c}\text { REGIME } \\
3 \\
\end{array}$ & $\begin{array}{c}\mu: 6,4574^{*} \\
\text { IED } 1: 0.1559\end{array}$ & 1995-T2 & 1996-T3 & 6 \\
\hline
\end{tabular}

Probabilidades de transição do modelo MS-

MN(4) para a série COMM - 1995-T1 até 2014-

$\mathrm{T} 4$

\begin{tabular}{c|cccc}
\hline COMM & Regime $0, \mathrm{t}$ & Regime 1,t & Regime 2,t & Regime 3, \\
\hline Regime $0, \mathrm{t}+1$ & 0,91952 & 0,03735 & 0,10862 & 0,00000 \\
Regime $1, \mathrm{t}+1$ & 0,00000 & 0,88761 & 0,00000 & 0,22299 \\
Regime 2, $\mathrm{t}+1$ & 0,08048 & 0,00000 & 0,89138 & 0,00000 \\
Regime $3, \mathrm{t}+1$ & 0,00000 & 0,07504 & 0,00000 & 0,77701 \\
\hline
\end{tabular}

Probabilidades de transição do modelo MS-

DR(2) para a série EXPORT - 1995-T1 até

\begin{tabular}{c|cc}
\multicolumn{3}{c}{ 2014-T4 } \\
\hline EXPORT & Regime 0, $\mathrm{t}$ & Regime 1, $\mathrm{t}$ \\
\hline Regime 0, $\mathrm{t}+1$ & 0,96437 & 0,07242 \\
Regime 1, $\mathrm{t}+1$ & 0,03563 & 0,92758 \\
\hline
\end{tabular}

Probabilidades de transição do modelo MSDR(3) para a série IEC - 1995-T1 até 2014-T4

\begin{tabular}{c|ccc}
\hline IEC & Regime 0, $\mathrm{t}$ & Regime 1, $\mathrm{t}$ & Regime 2, $\mathrm{t}$ \\
\hline Regime 0, $\mathrm{t}+1$ & 0,78946 & 0,02318 & 0,15740 \\
Regime 1, t+1 & 0,00000 & 0,97682 & 0,00000 \\
Regime 2, t+1 & 0,21054 & 0,00000 & 0,84260 \\
\hline
\end{tabular}

Probabilidades de transição do modelo MSDR(4) para a série IED - 1995-T1 até 2014-T4

\begin{tabular}{c|cccc}
\hline IED & Regime 0, $\mathrm{t}$ & Regime 1, $\mathrm{t}$ & Regime 2, & Regime 3, \\
\hline Regime 0, $\mathrm{t}+1$ & 0,92523 & 0,02446 & 0,00000 & 0,00000 \\
Regime 1, $\mathrm{t}+1$ & 0,00000 & 0,97553 & 0,00000 & 0,13887 \\
Regime 2, $\mathrm{t}+1$ & 0,07476 & 0,00000 & 1,00000 & 0,00000 \\
Regime 3, $\mathrm{t}+1$ & 0,00000 & 0,00000 & 0,00000 & 0,86113 \\
\hline
\end{tabular}




\section{Apêndice 3 \\ Estatísticas para as Análises VAR/VEC}

Teste de raiz unitária com quebra estrutural e teste ADF para as séries que serão empregadas nos modelos de cointegração bivariada e multivariada

\begin{tabular}{|c|c|c|c|c|c|c|c|c|}
\hline \multicolumn{5}{|c|}{ TESTE COM QUEBRA - MODELO IO } & \multicolumn{4}{|c|}{ TESTE ADF } \\
\hline Série e Quebra & $\mathrm{C} / \mathrm{Lag}$ & Est. $\mathrm{T}$ & $\mathrm{VC}^{*}$ & GI & C/Lag & Est. $\mathrm{T}$ & $\mathrm{VC}^{*}$ & GI \\
\hline $\begin{array}{c}\text { COMM } \\
\text { Quebra: 2008-T3 }\end{array}$ & $\begin{array}{c}\mathrm{c}+\mathrm{t}, 1 \\
\mathrm{c}+\mathrm{t}\end{array}$ & $-5,0847$ & $\begin{array}{ll}1 \% & -5,719 \\
5 \% & -5,174\end{array}$ & $\mathrm{I}(1)$ & c, 2 & $-2,0702$ & $\begin{array}{ll}1 \% & -3,562 \\
5 \% & -2,918\end{array}$ & $\mathrm{I}(1)$ \\
\hline $\begin{array}{c}\text { EXPORT } \\
\text { Quebra: } 2011-\mathrm{T} 3\end{array}$ & $\begin{array}{c}\mathrm{t}+\mathrm{c} \\
\mathrm{t}\end{array}$ & $-2,3597$ & $\begin{array}{ll}1 \% & -5,067 \\
5 \% & -4,443\end{array}$ & $\mathrm{I}(1)$ & c & $-2,3395$ & $\begin{array}{ll}1 \% & -3,562 \\
5 \% & -2,918\end{array}$ & $\mathrm{I}(1)$ \\
\hline $\begin{array}{c}\text { IEC } \\
\text { Quebra: } 2008-\mathrm{T3}\end{array}$ & $\begin{array}{l}\mathrm{c}+\mathrm{t} \\
\mathrm{c}+\mathrm{t}\end{array}$ & $-4,7091$ & $\begin{array}{ll}1 \% & -5,719 \\
5 \% & -5,175\end{array}$ & $\mathrm{I}(1)$ & $\mathrm{c}$ & $-1,5045$ & $\begin{array}{ll}1 \% & -3,562 \\
5 \% & -2,918\end{array}$ & $\mathrm{I}(1)$ \\
\hline $\begin{array}{c}\text { IED } \\
\text { Quebra: } 2008-T 3\end{array}$ & $\begin{array}{l}\mathrm{c} \\
\mathrm{c}\end{array}$ & $-3,885$ & $\begin{array}{c}10 \%-4,443 \\
5 \%-4,193\end{array}$ & $\mathrm{I}(1)$ & $\mathrm{c}+\mathrm{t}$ & $-3,9361$ & $\begin{array}{ll}1 \% & -4,144 \\
5 \% & -3,498\end{array}$ & $\mathrm{I}(0)$ \\
\hline $\begin{array}{c}\text { AB } \\
\text { Quebra: } 2009-\mathrm{T} 1\end{array}$ & $\begin{array}{c}\mathrm{c}, 1 \\
\mathrm{c}\end{array}$ & $-4,9829$ & $\begin{array}{ll}1 \% & -4,443 \\
5 \% & -4,193\end{array}$ & $\mathrm{I}(0)$ & $\mathrm{c}, 1$ & $-2,7676$ & $\begin{array}{ll}1 \% & -3,548 \\
5 \% & -2,912\end{array}$ & $\mathrm{I}(1)$ \\
\hline $\begin{array}{c}\text { Bovespa } \\
\text { Quebra: } 2007-\mathrm{T} 4\end{array}$ & $\begin{array}{c}\mathrm{t}+\mathrm{c} \\
\mathrm{t}\end{array}$ & $-4,6189$ & $\begin{array}{ll}1 \% & -5,067 \\
5 \% & -4,524\end{array}$ & $\mathrm{I}(0)$ & $\mathrm{c}$ & $-1,003$ & $\begin{array}{ll}1 \% & -3,546 \\
5 \% & -2,911\end{array}$ & $\mathrm{I}(1)$ \\
\hline $\begin{array}{c}\text { Cambio_r } \\
\text { Quebra: } 2011-T 1\end{array}$ & $\underset{\mathrm{t}}{\mathrm{c}+\mathrm{t}, 1}$ & $-4,8624$ & $\begin{array}{ll}1 \% & -5,067 \\
5 \% & -4,524\end{array}$ & $\mathrm{I}(0)$ & c & $-2,0385$ & $\begin{array}{ll}1 \% & -3,548 \\
5 \% & -2,912\end{array}$ & $\mathrm{I}(1)$ \\
\hline $\begin{array}{c}\text { Cambio_n } \\
\text { Quebra: } 2008-\mathrm{T} 4\end{array}$ & $\begin{array}{c}\mathrm{c}+\mathrm{t}, 1 \\
\mathrm{c}+\mathrm{t}\end{array}$ & $-4,8183$ & $\begin{array}{ll}1 \% & -5,719 \\
5 \% & -5,175\end{array}$ & $\mathrm{I}(1)$ & c & $-2,0433$ & $\begin{array}{ll}1 \% & -3,548 \\
5 \% & -2,912\end{array}$ & $\mathrm{I}(1)$ \\
\hline $\begin{array}{c}\text { Jones } \\
\text { Quebra: } 2008-\mathrm{T} 2\end{array}$ & $\begin{array}{c}\mathrm{c}+\mathrm{t}, 1 \\
\mathrm{c}\end{array}$ & $-5,2509$ & $\begin{array}{ll}1 \% & -5,347 \\
5 \% & -4,859\end{array}$ & $\mathrm{I}(1)$ & $\mathrm{c}+\mathrm{t}, 1$ & $-2,3175$ & $\begin{array}{ll}1 \% & -4,124 \\
5 \% & -3,489\end{array}$ & $\mathrm{I}(1)$ \\
\hline $\begin{array}{c}\text { D_juros } \\
\text { Quebra: 2005-T3 }\end{array}$ & $\begin{array}{c}\mathrm{c}, 1 \\
\mathrm{c}\end{array}$ & $-5,6856$ & $\begin{array}{ll}1 \% & -4,949 \\
5 \% & -4,443\end{array}$ & $\mathrm{I}(0)$ & $\mathrm{c}+\mathrm{t}, 1$ & $-4,1383$ & $\begin{array}{ll}1 \% & -4,124 \\
5 \% & -3,489\end{array}$ & $\mathrm{I}(0)$ \\
\hline $\begin{array}{c}\text { EMBI } \\
\text { Quebra: } 2004-\mathrm{T} 2\end{array}$ & $\begin{array}{c}\mathrm{c}, 1 \\
\mathrm{c}\end{array}$ & $-3,6012$ & $\begin{array}{ll}1 \% & -4,949 \\
5 \% & -4,443\end{array}$ & $\mathrm{I}(1)$ & $\mathrm{c}+\mathrm{t}, 1$ & $-2,3305$ & $\begin{array}{ll}1 \% & -4,124 \\
5 \% & -3,489\end{array}$ & $\mathrm{I}(1)$ \\
\hline $\begin{array}{c}\text { FED } \\
\text { Quebra: } 2004-\mathrm{T} 2\end{array}$ & $\begin{array}{c}\mathrm{c}+\mathrm{t}, 3 \\
\mathrm{c}\end{array}$ & $-4,7088$ & $\begin{array}{ll}1 \% & -5,719 \\
5 \% & -5,175\end{array}$ & $\mathrm{I}(1)$ & 1 & $-2,5241$ & $\begin{array}{ll}1 \% & -2.605 \\
5 \% & -1,946\end{array}$ & $\mathrm{I}(0)$ \\
\hline $\begin{array}{c}\text { IPCA } \\
\text { Quebra: } 2005-\mathrm{T} 4\end{array}$ & $\begin{array}{c}\mathrm{c}+\mathrm{t}, 1 \\
\mathrm{c}\end{array}$ & $-5,1441$ & $\begin{array}{ll}1 \% & -5,347 \\
5 \% & -4,859\end{array}$ & $\mathrm{I}(0)$ & $\mathrm{c}, 2$ & $-2,8502$ & $\begin{array}{ll}1 \% & -3,550 \\
5 \% & -2,913\end{array}$ & $\mathrm{I}(1)$ \\
\hline $\begin{array}{c}\text { PIB } \\
\text { Quebra: } 2012-\mathrm{T} 2\end{array}$ & $\underset{\mathrm{t}}{\mathrm{c}+\mathrm{t}, 1}$ & $-4,0865$ & $\begin{array}{ll}1 \% & -5,067 \\
5 \% & -4,524\end{array}$ & $\mathrm{I}(1)$ & 2 & $-2,4301$ & $\begin{array}{ll}1 \% & -2,611 \\
5 \% & -1,947\end{array}$ & $\mathrm{I}(0)$ \\
\hline $\begin{array}{c}\text { PIB_M } \\
\text { Quebra: } 2009-T 1\end{array}$ & $\begin{array}{c}\mathrm{c}, 1 \\
\mathrm{c}\end{array}$ & $-3,4196$ & $\begin{array}{ll}1 \% & -4,949 \\
5 \% & -4,443\end{array}$ & $\mathrm{I}(1)$ & $\mathrm{c}, 2$ & $-1,1552$ & $\begin{array}{ll}1 \% & -3,571 \\
5 \% & -2,922\end{array}$ & $\mathrm{I}(1)$ \\
\hline $\begin{array}{c}\text { SELIC } \\
\text { Quebra: } 2006-\mathrm{T3}\end{array}$ & $\begin{array}{c}\mathrm{c}+\mathrm{t}, 1 \\
\mathrm{c}\end{array}$ & $-6,2475$ & $\begin{array}{ll}1 \% & -5,347 \\
5 \% & -4,859\end{array}$ & $\mathrm{I}(0)$ & $\mathrm{c}+\mathrm{t}, 1$ & $-4,6862$ & $\begin{array}{ll}1 \% & -4,124 \\
5 \% & -3,489\end{array}$ & $\mathrm{I}(0)$ \\
\hline $\begin{array}{c}\text { SOL } \\
\text { Quebra: } 2003-\mathrm{T} 3\end{array}$ & $\begin{array}{c}\mathrm{c}+\mathrm{t} \\
\mathrm{t}\end{array}$ & $-4,002$ & $\begin{array}{ll}1 \% & -5,067 \\
5 \% & -4,524\end{array}$ & $\mathrm{I}(1)$ & c & $-0,8898$ & $\begin{array}{ll}1 \% & -3,546 \\
5 \% & -2,911\end{array}$ & $\mathrm{I}(1)$ \\
\hline $\begin{array}{c}\text { SOLL } \\
\text { Quebra: } 2003-\mathrm{T} 4\end{array}$ & $\begin{array}{c}\mathrm{c}+\mathrm{t}, 1 \\
\mathrm{c}\end{array}$ & $-4,7528$ & $\begin{array}{ll}1 \% & -5,347 \\
5 \% & -4,859\end{array}$ & $\mathrm{I}(1)$ & $\mathrm{c}$ & $-3,2408$ & $\begin{array}{ll}1 \% & -3,565 \\
5 \% & -2,919\end{array}$ & $\mathrm{I}(0)$ \\
\hline $\begin{array}{c}\text { AI } \\
\text { Quebra: } 2008-T 2\end{array}$ & $\begin{array}{l}\mathrm{c} \\
\mathrm{c}\end{array}$ & $-3,5942$ & $\begin{array}{ll}1 \% & -4,949 \\
5 \% & -4,443\end{array}$ & $\mathrm{I}(1)$ & $\mathrm{c}+\mathrm{t}$ & $-3,6634$ & $\begin{array}{ll}1 \% & -4,148 \\
5 \% & -3,500\end{array}$ & $\mathrm{I}(0)$ \\
\hline $\begin{array}{c}\text { PIB_M_tx } \\
\text { Quebra: } 2008-T 1\end{array}$ & $\begin{array}{c}\mathrm{c}, 5 \\
\mathrm{c}\end{array}$ & $-5,088$ & $\begin{array}{ll}1 \% & -4,949 \\
5 \% & -4,443\end{array}$ & $\mathrm{I}(0)$ & c, 6 & $-1,876$ & $\begin{array}{ll}1 \% & -3,584 \\
5 \% & -2,928\end{array}$ & $\mathrm{I}(1)$ \\
\hline $\begin{array}{c}\text { COMM_tx } \\
\text { Quebra: } 2008-T 3\end{array}$ & $\begin{array}{c}\mathrm{c}, 1 \\
\mathrm{c}\end{array}$ & $-7,6307$ & $\begin{array}{ll}1 \% & -5,347 \\
5 \% & -4,859\end{array}$ & $\mathrm{I}(0)$ & $\mathrm{c}+\mathrm{t}, 5$ & $-3,4952$ & $\begin{array}{ll}1 \% & -4,170 \\
5 \% & -3,510\end{array}$ & $\mathrm{I}(1)$ \\
\hline
\end{tabular}

Legenda: Coeficientes e lag (c/lag) indicam os parâmetros utilizados e a quantidade de defasagens empregadas nas estimações; Estatística-t (Est. T); Valor Crítico (VC); Grau de Interação (GI).*Considerando $5 \%$ de significância. Fonte: Estatísticas calculadas pelo programa Eviews 9 . 
A - Modelo de Exportações 2002-T1 até 2014-T4

Critérios de informação,

Heterocedasticidade e Autocorrelação

\begin{tabular}{|c|c|c|c|c|c|c|}
\hline & \multicolumn{2}{|c|}{ Ordem 2} & \multicolumn{2}{|c|}{ Ordem 3} & \multicolumn{2}{|c|}{ Ordem 4} \\
\hline & AIC & $\mathrm{S \textrm {SC }}$ & AIC & $\mathrm{SC}$ & AIC & $\mathrm{SC}$ \\
\hline & $-16,488$ & $-14,837$ & $-16,650$ & $-14,398$ & $-16,267$ & 13,415 \\
\hline \multicolumn{7}{|c|}{ Teste de Heterocedasticidade - White } \\
\hline & 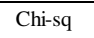 & p-valor & chi-sq & p-valor & chi-sq & p-valor \\
\hline & 245,47 & 0,000 & 296,47 & 0,059 & 378,86 & 0,071 \\
\hline \multicolumn{7}{|c|}{ Teste de Autocorrelacão Residual LM } \\
\hline ags & Estatística & $\mathrm{p}$-valor & Estatística & p-valor & Estatística & p-valor \\
\hline t & 21,948 & 0,144 & 7.342 & 0,966 & 15,798 & 0,467 \\
\hline 2 & 31,333 & 0,012 & 13,748 & 0,617 & 15,927 & 0,458 \\
\hline 3 & 21,914 & 0,146 & 7,543 & 0,961 & 18,607 & 0,289 \\
\hline 4 & 11.527 & 0,775 & 4,921 & 0,996 & 2,443 & 1,000 \\
\hline & 9.248 & 0.902 & 15,158 & 0.513 & 16350 & 0.428 \\
\hline
\end{tabular}

Teste de Johansen

Nr. de Estatística $\quad$ Estatística

equações $\begin{gathered}\text { Estatística } \\ \text { do Traço }\end{gathered}$

cointegradas do Traço P-valo Mherovalor

\begin{tabular}{lllll}
\hline \hline Nenhuma & 81,633 & 0,001 & 42,021 & 0,001 \\
\hline
\end{tabular}

$\begin{array}{lllll}\leq 1 & 39,613 & 0,103 & 25,165 & 0,103\end{array}$

$\begin{array}{lllll}\leq 2 & 14,448 & 0,621 & 11,725 & 0,621\end{array}$

\begin{tabular}{rrrr}
14,448 & 0,621 & 11,725 & 0,621 \\
2,723 & 0,908 & 2,723 & 0,908 \\
\hline
\end{tabular}

$0,908 \quad \triangle \mathrm{PO}^{\prime}$

$\triangle \mathrm{COM}$ _M não causa $\triangle \mathrm{CAMBIO}$

$\triangle$ COMM não causa $\triangle$ EXPORT

$\begin{array}{ll}12,7941 & 4,00 E-06 \\ \triangle E X P O R T \text { ก̃̃o }\end{array}$

\begin{tabular}{lll}
\hline & 0,9329 \\
\hline
\end{tabular}

$\begin{array}{lll}\triangle E \text { EXPORT não causa } \triangle \text { CAMBIO_: } & 1,71458 & 0,1786 \\ \triangle \text { CAMBIO_R ño causa } \triangle \text { COMMM } & 045222 & 0,717\end{array}$

\begin{tabular}{lll}
$\Delta$ COMM não causa $\triangle$ CAMBIO_R & 0,45222 & 0,717 \\
& 0,37532 & 0,7712 \\
\hline
\end{tabular} 
Sabrina Monique Schenato Bredow, Marcos Tadeu Caputi Lélis, André Moreira Cunha

B - Modelo de IEC 2002-T1 até 2014-T4

Critérios de informação, Heterocedasticidade e Autocorrelação

\begin{tabular}{ccc|cc} 
& \multicolumn{4}{c}{ IEC } \\
\cline { 2 - 5 } & \multicolumn{2}{c}{ Ordem 2 } & \multicolumn{2}{c}{ Ordem 3 } \\
\cline { 2 - 5 } & AIC & SC & AIC & SC \\
& $-11,756$ & $-5,888$ & $-13,315$ & $-4,895$ \\
\hline \multicolumn{2}{c}{ Teste de Heterocedasticidade - White } \\
\cline { 2 - 5 } & Chi-sq & p-valor & chi-sq & p-valor \\
\multicolumn{6}{c}{1202,32} & 0,665 & $*$ & $*$ \\
\cline { 2 - 5 } & \multicolumn{2}{c}{ Teste de } & Autocorrelação Residual LM \\
\hline lags & Estatística & p-valor & Estatística & p-valor \\
1 & 78,900 & 0,100 & 63,088 & 0,509 \\
2 & 61,049 & 0,582 & 55,642 & 0,762 \\
3 & 73,462 & 0,196 & 66,039 & 0,406 \\
4 & 63,133 & 0,507 & 83,532 & 0,051 \\
5 & 92,224 & 0,012 & 68,687 & 0,322 \\
\hline
\end{tabular}

Teste de Johansen

\begin{tabular}{lrrrr}
\hline $\begin{array}{c}\text { Nr. de } \\
\text { equações } \\
\text { cointegradas }\end{array}$ & $\begin{array}{c}\text { Estatística do } \\
\text { Traço }\end{array}$ & P-valor & $\begin{array}{c}\text { Estatística } \\
\text { Máximo- } \\
\text { autovalor }\end{array}$ & P-valor \\
\hline \hline Nenhuma & 339,329 & 0,000 & 103,880 & 0,000 \\
$\leq 1$ & 235,449 & 0,000 & 75,096 & 0,000 \\
$\leq 2$ & 160,353 & 0,000 & 52,520 & 0,001 \\
$\leq 3$ & 107,834 & 0,000 & 49,579 & 0,000 \\
$\leq 4$ & 58,254 & 0,004 & 29,339 & 0,030 \\
$\leq 5$ & 28,915 & 0,063 & 18,113 & 0,126 \\
$\leq 6$ & 10,802 & 0,224 & 10,632 & 0,174 \\
$\leq 7$ & 0,169 & 0,681 & 0,169 & 0,681 \\
\hline & & & & \\
& & & & \\
& & & &
\end{tabular}

Causalidade de Granger para as variáveis endógenas

\begin{tabular}{|c|c|c|}
\hline Tula & Estatística & P-valor \\
\hline$\overline{\Delta C O M M}$ não causa $\triangle \mathrm{IEC}$ & 1,5899 & 0,2152 \\
\hline & & \\
\hline$\Delta D_{\text {D_juros não causa }} \triangle \mathrm{IEC}$ & 0,1334 & 0,8755 \\
\hline$\Delta \mathrm{IEC}$ não causa $\Delta \mathrm{D}_{\text {_juros }}$ & 0,5047 & 0,6071 \\
\hline$\triangle \mathrm{EMBI}$ não causa $\triangle \mathrm{IEC}$ & 0,2058 & 0,8148 \\
\hline$\triangle \mathrm{IEC}$ não causa $\triangle \mathrm{EMBI}$ & 0,8468 & 0,4355 \\
\hline$\Delta$ Cambio_n não causa $\triangle \mathrm{IEC}$ & 2,4148 & 0,1009 \\
\hline$\Delta \mathrm{IEC}$ não causa $\Delta$ Cambio_n & 0,0311 & 0,9694 \\
\hline$\triangle$ Bovespa não causa $\triangle \mathrm{IEC}$ & 2,7703 & 0,0733 \\
\hline$\Delta \mathrm{IEC}$ does não causa $\Delta$ bovespa & 1,5557 & 0,2222 \\
\hline$\triangle$ JONES não causa $\triangle \mathrm{IEC}$ & 1,2453 & 0,2976 \\
\hline$\triangle \mathrm{IEC}$ não causa $\triangle \mathrm{JONES}$ & 0,3258 & 0,7236 \\
\hline$\triangle$ SOLL não causa $\triangle I E C$ & 0,7481 & 0,4792 \\
\hline$\triangle \mathrm{IEC}$ não causa $\triangle \mathrm{SOLL}$ & 1,5129 & 0,2315 \\
\hline$\triangle \mathrm{D} \_$JUROS não causa $\triangle \mathrm{COMM}$ & 1,5358 & 0,2263 \\
\hline$\triangle \mathrm{COMM}$ não causa $\triangle \mathrm{D} \_J U R O S$ & 3,0407 & 0,0577 \\
\hline$\triangle \mathrm{EMBI}$ não causa $\triangle \mathrm{COMM}$ & 0,4115 & 0,6651 \\
\hline$\triangle \mathrm{COMM}$ não causa $\triangle \mathrm{EMBI}$ & 0,8067 & 0,4527 \\
\hline$\Delta$ Cambio_n não causa $\Delta \mathrm{COMM}$ & 0,9978 & 0,3767 \\
\hline$\Delta$ COMM não causa $\Delta$ Cambio $\_n$ & 0,6494 & 0,5272 \\
\hline$\Delta$ Bovespa não causa $\triangle \mathrm{COMM}$ & 1,5260 & 0,2284 \\
\hline$\triangle \mathrm{COMM}$ não causa $\triangle$ bovespa & 4,1236 & 0,0227 \\
\hline$\Delta$ Jones não causa $\triangle \mathrm{COMM}$ & 0,7114 & 0,4964 \\
\hline$\Delta$ COMM não causa $\Delta$ Jones & 5,6445 & 0,0065 \\
\hline$\triangle$ SOLL não causa $\triangle \mathrm{COMM}$ & 3,3480 & 0,0443 \\
\hline$\triangle \mathrm{COMM}$ não causa $\Delta \mathrm{SOLL}$ & 8,0554 & 0,0010 \\
\hline
\end{tabular}


O ciclo de alta nos preços das commodities e a economia brasileira: uma análise dos mecanismos...

C - Modelo de IED 2002-T1 até 2014-T4

Critérios de informação,

\begin{tabular}{|c|c|c|c|c|c|c|c|c|c|}
\hline \multirow{2}{*}{\multicolumn{5}{|c|}{ Heterocedasticidade e Autocorrelação }} & \multirow{3}{*}{$\begin{array}{c}\text { Nr. de } \\
\text { equações } \\
\text { cointegradas }\end{array}$} & & & & \\
\hline & & & & & & \multirow{2}{*}{$\begin{array}{l}\text { Estatistica } \\
\text { do Traço }\end{array}$} & \multirow[b]{2}{*}{ P-valor } & \multirow{2}{*}{$\begin{array}{l}\text { Estatistica } \\
\text { Máximo- } \\
\text { autovalor } \\
\end{array}$} & \multirow{2}{*}{ P-valor } \\
\hline & \multicolumn{2}{|c|}{ Ordem 2} & \multicolumn{2}{|c|}{ Ordem 3} & & & & & \\
\hline & AIC & $\mathrm{SC}$ & AIC & & Nenhuma & 425,906 & 0,000 & 109,637 & 0,000 \\
\hline & $-16,864$ & $-9,637$ & $-19,733$ & $-9,308$ & $\leq 1$ & 316,269 & 0,000 & 78,855 & 0,000 \\
\hline & \multicolumn{4}{|c|}{ Teste de Heterocedasticidade - White } & $\leq 2$ & 237,414 & 0,000 & 67,172 & 0,000 \\
\hline & Chi-sq & p-valor & chi-sq & p-valor & $\leq 3$ & 170,242 & 0,000 & 50,245 & 0,003 \\
\hline & 1740,86 & 0,296 & & * & $\leq 4$ & 119,996 & 0,000 & 38,930 & 0,012 \\
\hline & \multicolumn{4}{|c|}{ Teste de Autocorrelacão Residual LM } & $\leq 5$ & $\$ 1,067$ & 0,000 & 28,816 & 0,035 \\
\hline lags & Estatistica & p-valor & Estatistica & p-valor & $\leq 0$ & 52,251 & 0,000 & 24,617 & 0,016 \\
\hline 1 & 79,738 & 0.519 & 106,644 & 0.030 & $\leq 1$ & 27,634 & 0,001 & 14,639 & 0,044 \\
\hline 2 & 90,418 & 0,222 & 90,304 & 0,225 & $\underline{1}$ & 12,996 & 0,000 & 12,996 & 0,000 \\
\hline 3 & 91,500 & 0199 & 78289 & 0565 & & & & & \\
\hline 4 & 89,969 & 0,232 & 104,798 & 0,039 & & & & & \\
\hline 5 & 62,252 & 0,940 & 92,029 & 0,189 & & & & & \\
\hline
\end{tabular}

Causalidade de Granger para as variáveis endógenas

\begin{tabular}{|c|c|c|}
\hline Hipótese Nula & Estatística & P-valor \\
\hline$\overline{\Delta C O M M \_t x \text { não causa } \Delta \mathrm{IED}}$ & 2,962 & 0,062 \\
\hline$\Delta \mathrm{IED}$ não causa $\Delta \mathrm{COMM} \_\mathrm{tx}$ & 0,512 & 0,603 \\
\hline$\Delta \mathrm{PIB}$ não causa $\triangle \mathrm{IED}$ & 4,392 & 0,018 \\
\hline$\Delta \mathrm{IED}$ não causa $\triangle \mathrm{PIB}$ & 0,948 & 0,395 \\
\hline$\Delta \mathrm{PIB} \_\mathrm{M} \_$tx não causa $\Delta \mathrm{IED}$ & 2,724 & 0,076 \\
\hline$\Delta \mathrm{IED}$ não causa $\triangle \mathrm{PIB} \_\mathrm{M} \_\mathrm{tx}$ & 0,265 & 0,768 \\
\hline$\Delta \mathrm{AI}$ não causa $\Delta \mathrm{IED}$ & 1,000 & 0,376 \\
\hline$\Delta \mathrm{IED}$ não causa $\Delta \mathrm{AI}$ & 0,061 & 0,941 \\
\hline$\triangle \mathrm{AB}$ não causa $\triangle \mathrm{IED}$ & 0,574 & 0,568 \\
\hline$\triangle \mathrm{IIED}$ não causa $\triangle \mathrm{AB}$ & 0,367 & 0,695 \\
\hline$\Delta$ Cambio_n não causa $\Delta \mathrm{IED}$ & |1,972 & 0,151 \\
\hline$\Delta \mathrm{IED}$ não causa $\Delta$ Cambio_n & 0,999 & 0,376 \\
\hline$\triangle \mathrm{IPCA}$ não causa $\triangle \mathrm{IED}$ & 1,338 & 0,273 \\
\hline$\triangle \mathrm{IED}$ não causa $\triangle \mathrm{IPCA}$ & 0,368 & 0,694 \\
\hline$\triangle \mathrm{FED}$ não causa $\triangle \mathrm{IED}$ & 0,449 & 0,641 \\
\hline$\Delta \mathrm{IED}$ não causa $\triangle \mathrm{FED}$ & 0,969 & 0,387 \\
\hline$\Delta \mathrm{PIB}$ não causa $\Delta$ COMM_tx & 1,368 & 0,265 \\
\hline$\Delta$ COMM_tx não causa $\triangle \mathrm{PIB}$ & 4,278 & 0,020 \\
\hline$\Delta$ PIB_M_TX não causa $\triangle \mathrm{COMM} \_t \mathrm{x}$ & 9,033 & 0,001 \\
\hline$\Delta$ COMM_tx não causa $\triangle$ PIB_M_tx & 6,006 & 0,005 \\
\hline$\triangle \mathrm{AI}$ não causa $\triangle \mathrm{COMM} \_\mathrm{tx}$ & 0,745 & 0,480 \\
\hline$\Delta$ COMM_tx não causa $\Delta \mathrm{AI}$ & 1,282 & 0,287 \\
\hline$\triangle \mathrm{AB}$ não causa $\Delta \mathrm{COMM} \_\mathrm{tx}$ & 1,491 & 0,236 \\
\hline$\Delta$ COMM_tx não causa $\triangle \mathrm{AB}$ & 5,964 & 0,005 \\
\hline$\Delta$ Cambio_n não causa $\triangle$ COMM_tx & 1,943 & 0,155 \\
\hline$\Delta$ COMM_tx não causa $\Delta$ Cambio_n & 0,434 & 0,651 \\
\hline$\Delta \mathrm{IPCA}$ não causa $\Delta \mathrm{COMM} \_$tx & 0,169 & 0,845 \\
\hline$\triangle \mathrm{COMM} \_$tx não causa $\triangle \mathrm{IPCA}$ & 2,029 & 0,143 \\
\hline$\Delta \mathrm{FED}$ não causa $\triangle \mathrm{COMM}_{\mathrm{C}} \mathrm{tx}$ & 4,889 & 0,012 \\
\hline$\triangle \mathrm{COMM}_{\mathrm{N}} \mathrm{tx}$ não causa $\triangle \mathrm{FED}$ & {$[0,147$} & 0,864 \\
\hline
\end{tabular}


Sabrina Monique Schenato Bredow, Marcos Tadeu Caputi Lélis, André Moreira Cunha 